\title{
Gamma-Glutamylpolyamine Synthetase GInA3 Is Involved in the First Step of Polyamine Degradation Pathway in Streptomyces coelicolor M145
}

\author{
Sergii Krysenko, Nicole Okoniewski, Andreas Kulik, Arne Matthews, Jan Grimpo, \\ Wolfgang Wohlleben and Agnieszka Bera*
}

Interfaculty Institute of Microbiology and Infection Medicine Tübingen, Department of Microbiology and Biotechnology, University of Tübingen, Tübingen, Germany

\section{OPEN ACCESS}

Edited by:

Biswarup Mukhopadhyay,

Virginia Tech, USA

Reviewed by:

Larry Reitzer

University of Texas at Dallas, USA

Marie-Joelle Virolle,

Centre National de la Recherche

Scientifique (CNRS), France

*Correspondence:

Agnieszka Bera

agnieszka.bera@biotech.unituebingen.de

Specialty section:

This article was submitted to Microbial Physiology and Metabolism,

a section of the journal

Frontiers in Microbiology

Received: 04 January 2017

Accepted: 07 April 2017

Published: 25 April 2017

Citation:

Krysenko S, Okoniewski N, Kulik A, Matthews A, Grimpo J,

Wohlleben W and Bera A (2017)

Gamma-Glutamylpolyamine

Synthetase GInA3 Is Involved

in the First Step of Polyamine

Degradation Pathway

in Streptomyces coelicolor M145.

Front. Microbiol. 8:726.

doi: 10.3389/fmicb.2017.00726
Streptomyces coelicolor M145 was shown to be able to grow in the presence of high concentrations of polyamines, such as putrescine, cadaverine, spermidine, or spermine, as a sole nitrogen source. However, hardly anything is known about polyamine utilization and its regulation in streptomycetes. In this study, we demonstrated that only one of the three proteins annotated as glutamine synthetase-like protein, GInA3 (SCO6962), was involved in the catabolism of polyamines. Transcriptional analysis revealed that the expression of glnA3 was strongly induced by exogenous polyamines and repressed in the presence of ammonium. The $\triangle g / n A 3$ mutant was shown to be unable to grow on defined Evans agar supplemented with putrescine, cadaverine, spermidine, and spermine as sole nitrogen source. HPLC analysis demonstrated that the $\triangle g \ln A 3$ mutant accumulated polyamines intracellularly, but was unable to degrade them. In a rich complex medium supplemented with a mixture of the four different polyamines, the $\Delta g / n A 3$ mutant grew poorly showing abnormal mycelium morphology and decreased life span in comparison to the parental strain. These observations indicated that the accumulation of polyamines was toxic for the cell. An in silico analysis of the GlnA3 protein model suggested that it might act as a gamma-glutamylpolyamine synthetase catalyzing the first step of polyamine degradation. GlnA3-catalyzed glutamylation of putrescine was confirmed in an enzymatic in vitro assay and the GlnA3 reaction product, gamma-glutamylputrescine, was detected by HPLC/ESI-MS. In this work, the first step of polyamine utilization in $S$. coelicolor has been elucidated and the putative polyamine utilization pathway has been deduced based on the sequence similarity and transcriptional analysis of homologous genes expressed in the presence of polyamines.

Keywords: nitrogen assimilation, Streptomyces coelicolor, GS-like enzyme, GInA3, polyamine utilization, gamma-glutamylpolyamine synthetase

\section{INTRODUCTION}

Streptomyces coelicolor is a Gram-positive, non-motile, soil-dwelling bacterium that belongs to genus Streptomyces, phylum Actinobacteria. It can assimilate nitrogen from a variety of mineral (e.g., ammonium, nitrate, and nitrite) and organic sources (e.g., urea, amino acids, peptides, and amino sugars). However, nitrogen sources such as polyamines, which are also omnipresent in 
nature, have never been reported to be utilized by $S$. coelicolor. Polyamines are widespread in all life kingdoms. Common polyamines include cadaverine, putrescine, spermidine, and spermine. Polyamines can be synthesized de novo or taken up from the environment. They are predominantly derived from the following amino acids: ornithine, arginine, and lysine (Kusano and Suzuki, 2015; Miller-Fleming et al., 2015). The canonical biosynthesis pathway begins with decarboxylation of either ornithine or arginine to form putrescine or decarboxylation of lysine to generate cadaverine (Kusano and Suzuki, 2015; MillerFleming et al., 2015). Putrescine serves as a substrate for spermine and spermidine biosynthesis via addition of aminopropyl groups donated by the decarboxylated $S$-adenosylmethionine (Kusano and Suzuki, 2015; Miller-Fleming et al., 2015).

Polyamines have been implicated in a wide range of biological processes, thus their intracellular concentration as well as metabolism is tightly regulated (Miller-Fleming et al., 2015). Extensive studies have demonstrated that intracellular polyamine concentrations accumulate during exposure to several stress conditions (reviewed in Miller-Fleming et al., 2015). In bacterial cells, the role of polyamines is less clear and depends on ecological and physiological context. In bacteria, some studies suggest that polyamines might be involved in cell growth stimulation (Yoshida et al., 2004; Igarashi and Kashiwagi, 2006), biofilm formation (Wortham et al., 2007; Lee et al., 2009; Nesse et al., 2015) as well as regulation of translation (Algranati et al., 1976; Nastri et al., 1993; Higashi et al., 2006; Terui et al., 2012) and transcription (Jain and Tyagi, 1987; Huang et al., 1990; Sarkar et al., 1995; Chattopadhyay et al., 2015). Some studies also suggest that they are involved in acid resistance (Jung and Kim, 2003a; Chattopadhyay and Tabor, 2013; Schneider et al., 2013) and the response to oxidative stress (Chattopadhyay et al., 2003; Jung and Kim, 2003b; Tkachenko and Nesterova, 2003; Sakamoto et al., 2015), biosynthesis of siderophores (Griffiths et al., 1984; Brickman and Armstrong, 1996; Oves-Costales et al., 2008; Burrell et al., 2012), SOS system activation (Oh and Kim, 1999) and antibiotic resistance (Nastri and Algranati, 1996; Kwon and Lu, 2006; Tkachenko et al., 2006; Sarathy et al., 2013).

In eukaryotes, polyamines have been described to be implicated in cell growth and development (Pirnes-Karhu et al., 2015; Reis et al., 2016), maturation (Zhou et al., 2009; Tsaniklidis et al., 2016) and proliferation (Heby, 1981; Dudkowska et al., 2003; Maeda et al., 2006; Bercovich et al., 2011; Weiger and Hermann, 2014). They were also reported to be involved in environmental stress response (Valdes-Santiago and RuizHerrera, 2013; Alcazar and Tiburcio, 2014; Minocha et al., 2014; Liu et al., 2015; Pal et al., 2015), defense response (Walters, 2003; Wimalasekera et al., 2011; Zeier, 2013; Hatmi et al., 2014; Mo et al., 2015; Rossi et al., 2015) and apoptosis (Moschou and Roubelakis-Angelakis, 2014; Parhamifar et al., 2014; Cai et al., 2015). Polyamines are positively charged molecules able to interact with negatively charged molecules like RNA, DNA, proteins, polyphosphate, and phospholipids (Norris et al., 2015). Consequently, an imbalance in polyamine metabolism can deeply affect cellular homeostasis. Abolished polyamine biosynthesis leads to a reduction in growth rate in E. coli. (Cunningham-Rundles and Maas, 1975) and to complete arrest of cell proliferation in eukaryotic cells (Pitkin and Davis, 1990; Ray et al., 1999; Chattopadhyay et al., 2002; Odenlund et al., 2009). Polyamine excess is toxic for prokaryotic and eukaryotic organisms (Davis and Ristow, 1991; Tome et al., 1997; Pegg, 2013; Miller-Fleming et al., 2015), hence polyamine uptake and utilization as well as biosynthesis are under strict regulation (Kusano and Suzuki, 2015; Miller-Fleming et al., 2015).

Although polyamine biosynthesis has been broadly studied in evolutionary diverse bacteria and archaea (Tabor and Tabor, 1985; Sekowska et al., 1998; Lee et al., 2009; Nguyen et al., 2015), polyamine catabolism has been mostly studied in gram negative bacteria (Foster et al., 2013; Kusano and Suzuki, 2015). Polyamine utilization pathway is not universal for all bacteria. The currently known polyamine degradative pathways in prokaryotes are summarized in Figure 1. These include the $\gamma$-glutamylation pathway, aminotransferase pathway, spermine/spermidine dehydrogenase pathway, direct oxidation pathway and acetylation pathway (Figure 1). However, concerning the acetylation pathway it remains unclear whether acetylated polyamines are further metabolized or excreted (Forouhar et al., 2005; Bai et al., 2011; Planet et al., 2013; Campilongo et al., 2014; Nguyen et al., 2015). Gram-negative bacteria such as E. coli and $P$. aeruginosa degrade putrescine via GABA to succinate through two pathways: the $\gamma$-glutamylation pathway (Kurihara et al., 2005; Yao et al., 2011; Schneider and Reitzer, 2012) and the aminotransferase pathway (Shaibe et al., 1985; Schneider and Reitzer, 2012) (Figure 1). The initial step of the $\gamma$-glutamylation pathway involves the glutamylation of putrescine by the $\gamma$-glutamylpolyamine synthetase (PuuA) first reported in E. coli (Kurihara et al., 2005). Remarkably, P. aeruginosa possess expanded polyamine catabolic pathway involving seven related $\gamma$-glutamylpolyamine synthetases (PauA1-PauA7), each specific for polyamines, monoamines, or other substrates (Yao et al., 2011).

Interestingly, the reaction catalyzed by $\gamma$-glutamylpolyamine synthetase is comparable to the reaction catalyzed by glutamine synthetase (GS). Both enzymes are able to ligate L-glutamate with an amino group of the specific substrate (polyamine or ammonium, respectively) using energy from ATP. Moreover, both enzyme types share structural similarities (Ladner et al., 2012). Consequently, some proteins annotated as glutamine synthetase-like enzymes (GS-like) may represent still not recognized $\gamma$-glutamylpolyamine synthetases. Indeed, Streptomyces coelicolor A3(2) harbors two genes, glnA (SCO2198) and $g \ln I I$ (SCO2210), encoding GSI and GSII, whose function and regulation was extensively studied (Hillemann et al., 1993; Fink et al., 1999; Weisschuh et al., 2000) as well as three other genes, $g \ln A 2$ (SCO2241), $g \ln A 3$ (SCO6962), and $g \ln A 4$ (SCO1613), annotated as encoding putative GS-like enzymes (Rexer et al., 2006). In silico analysis of all $g \ln A$-like genes: $g \ln A 2, g \ln A 3$, and $g \ln A 4$ across the actinobacterial genomes revealed that $g \ln A$ has evolved to specialized $g \ln A$-like genes encoding proteins that might be involved in the colonization and survival in many diverse habitats (Hayward et al., 2009). Distinct ecological niches occupied by actinobacteria exerted specific evolutional pressure on GS genes resulting in diverse, but so far uncharacterized genes (Hayward et al., 2009). Actinobacterial 


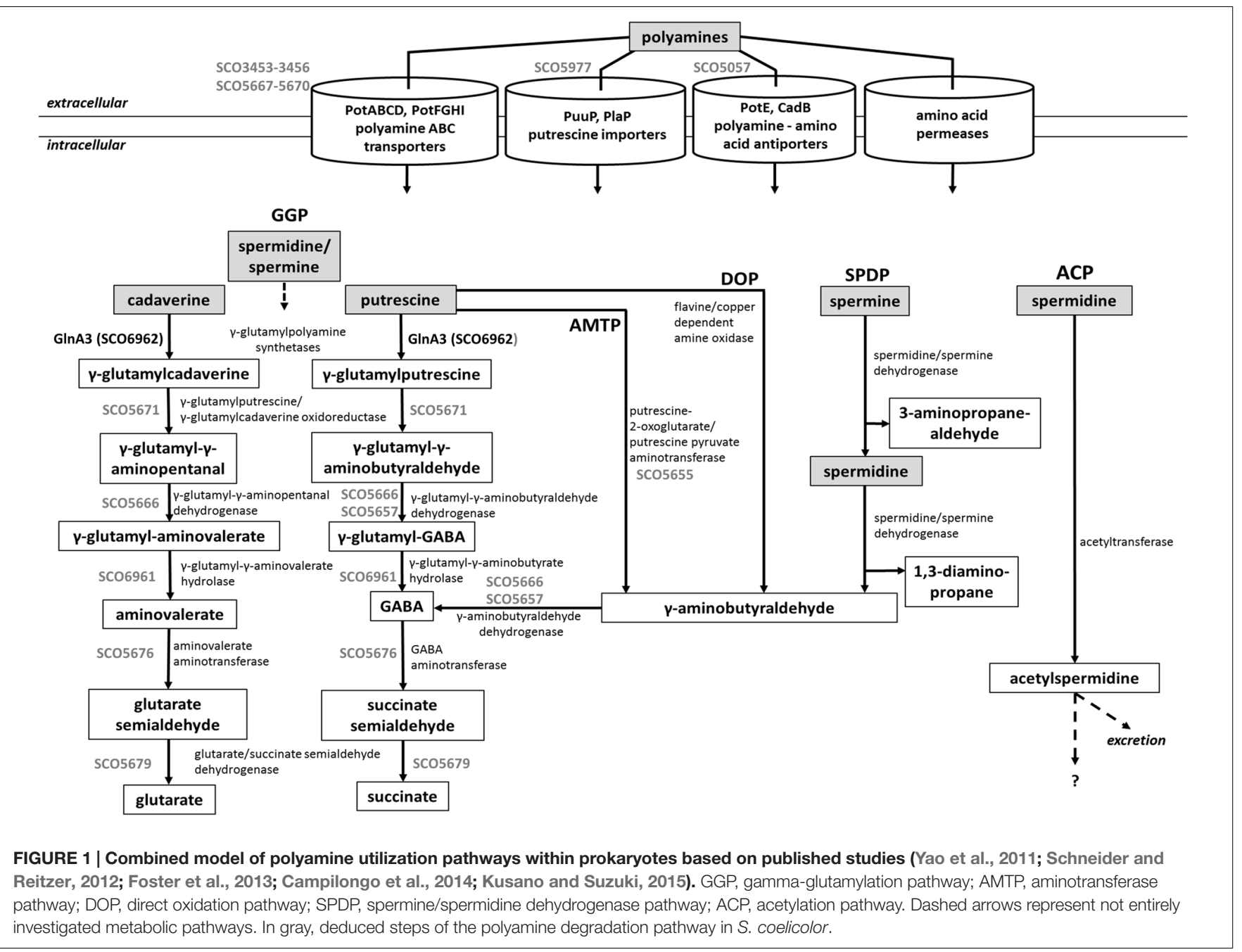

GSI-like enzymes, whose function is unknown (Rexer et al., 2006) were reported to be poorly expressed and their presence in the cell was judged as not essential for bacterial homeostasis at least under laboratory conditions (Harth et al., 2005). In this work, we demonstrated the involvement of the GSI-like enzyme - GlnA3, a gamma-glutamylpolyamine synthetase, in the polyamine degradation in S. coelicolor M145.

\section{MATERIALS AND METHODS}

\section{Strains and Growth Conditions}

Streptomyces coelicolor M145 (parental strain) and mutants were cultured for $4-6$ days at $30^{\circ} \mathrm{C}$ on the defined Evans-agar base (modified after Evans et al., 1970) supplemented with different nitrogen sources: $50 \mathrm{mM}$ monosodium glutamate, L-glutamine, ammonium chloride, sodium nitrate, urea, cadaverine dihydrochloride, putrescine dihydrochloride, spermidine trihydrochloride and spermine tetrahydrochloride in appropriate concentrations. Growth experiments in liquid culture were performed using either complex S-medium
(Okanishi et al., 1974) or YEME:TSB (1:1) (Kieser et al., 2000) and chemically defined medium Evans-medium (modified after Evans et al., 1970). If appropriate, media were supplemented with polyamines or ammonium chloride as a sole nitrogen source. Strains were cultivated at $30^{\circ} \mathrm{C}$, on the rotary shaker $(180 \mathrm{rpm})$ for 4-6 days. Genetic manipulation of S. coelicolor M145 was performed as described by Kieser et al. (2000) and Gust et al. (2003). For preparation of the genomic DNA, S. coelicolor M145 was grown for 4 days in S-medium and DNA was isolated with the NucleoSpin Tissue Kit (Macherey-Nagel). All strains and plasmids used in this study are listed in the Table $\mathbf{1}$.

\section{Construction of the $\triangle g \ln A 3$ Complementation Mutant}

To perform a complementation of the mutant, $g \ln A 3$ gene without its native promoter was amplified by PCR using $\mathrm{Cg} \ln \mathrm{A} 3 \mathrm{f}$ and $\mathrm{Cg} \ln \mathrm{A} 3 \mathrm{r}$ primers (Table 2) and cloned into the multiple cloning site of pRM4 plasmid. The correct construct was confirmed by sequencing and subsequently introduced into the $\triangle g \ln A 3$ mutant by conjugation using the E. coli S17 strain. Clones were then selected on resistant 
TABLE 1 | Strains and plasmids used in this study.

\begin{tabular}{|c|c|c|}
\hline Strains & Genotype & Reference \\
\hline E. coli BW25113 & K-12 derivative ( $\triangle$ araBAD $\triangle r h a B A D$ ) carrying plasmid plJ790, $\mathrm{Cm}^{R}$ & Datsenko and Wanner, 2000 \\
\hline E. coli ET12567 & dam-13::Tn9, dcm-6, hsdM, Cm ${ }^{R}$, carrying helper plasmid pUZ8002 & MacNeil et al., 1992 \\
\hline E. coli XL1-Blue & $\begin{array}{l}\text { recA1, endA1 gyrA96, thi-1, hsdR17, supE44, relA1, lac [F' proAB } \\
\left.\text { laclaZ } \Delta \mathrm{M} 15 \mathrm{Tn}^{\prime} 10 \mathrm{Tet}^{R}\right]\end{array}$ & Bullock et al., 1987 \\
\hline S. coelicolor M145 & S. coelicolor A3(2) without native plasmids: $s p c 1^{-}$and $s p c 2^{-}$ & Kieser et al., 2000 \\
\hline S. coelicolor M145 $\Delta g \ln A$ & $\begin{array}{l}\text { glnA mutant strain of } S \text {. coelicolor M145; glnA replaced by an aac(3)IV } \\
\text { cassette, } \mathrm{Apr}^{R}\end{array}$ & Fink et al., 1999 \\
\hline S. coelicolor M145 $\Delta$ glnll & $\begin{array}{l}\text { glnll mutant strain of } S \text {. coelicolor M145; gln/l replaced by an aac(3)IV } \\
\text { cassette, } \mathrm{Apr}^{R}\end{array}$ & Tiffert et al., 2011 \\
\hline S. coelicolor M145 $\Delta g \ln A \Delta g \ln l l$ & $\begin{array}{l}\text { glnAglnll double deletion mutant strain of S. coelicolor M145; } \mathrm{Apr}^{R} \text { and } \\
\operatorname{Hyg}^{R}\end{array}$ & This work \\
\hline S. coelicolor M145 $\Delta g \ln A 2$ & $\begin{array}{l}\text { glnA2 mutant strain of S. coelicolor M145; insertional inactivation of } \\
\text { glnA2 by an aac(3)IV cassette, } \mathrm{Apr}^{R}\end{array}$ & Nentwich, 2010 \\
\hline S. coelicolor M145 $\Delta$ glnA3 & $\begin{array}{l}\text { glnA3 mutant strain of } S \text {. coelicolor M145; insertional inactivation of } \\
\text { glnA3 by an aac(3)IV cassette, } \mathrm{Apr}^{R}\end{array}$ & Rexer et al., 2006 \\
\hline S. coelicolor M145 $\Delta$ glnA4 & $\begin{array}{l}\text { glnA4 mutant strain of } S \text {. coelicolor M145; glnA4 replaced by an } \\
\text { aac(3)IV cassette, } \operatorname{Apr}^{R}\end{array}$ & This work \\
\hline S. coelicolor M145 $\Delta g \ln A 3 p R M 4 g \ln A 3$ & $\begin{array}{l}\text { Complemented glnA3 mutant strain of S. coelicolor M145; } \mathrm{Apr}^{R} \text { and } \\
\mathrm{Km}^{R}\end{array}$ & This work \\
\hline pRM4 & pSET152ermEp* with artificial RBS, Apr ${ }^{R}$ & Menges et al., 2007 \\
\hline plJ10700 & pBluescript II KS(+) containing hyg-oriT cassette, $\mathrm{Hyg}^{R}$ & Gust et al., 2003 \\
\hline pJOE2775 & pBR322-derived vector with Prha expression cassette & Volff et al., 1996 \\
\hline cosmid St3H12 & $\mathrm{Amp}^{R}, \mathrm{Kan}^{R}$ & Redenbach et al., 1996 \\
\hline
\end{tabular}

phenotype against kanamycin and apramycin. The correct integration of the pRM4-glnA3 was confirmed by PCR and sequencing.

\section{Construction of $\Delta g \ln A \Delta g|n| l$ Mutant}

REDIRECT gene-replacement procedure (Gust et al., 2003) was employed to generate in-frame deletion of the $g \ln I I$ gene (SCO2210) in previously generated $\Delta g \ln A$ mutant (Fink et al., 1999). The $g \operatorname{lnII}$ gene on the cosmid St3H12 was replaced by a hygromycin resistance cassette in $E$. coli BW25113. The hygromycin resistance cassette was amplified by PCR using glnII_hygr_P1 and $g \ln I I$ hygr_P2 primers. The obtained cosmid St3H12 $\Delta g \ln I I$ was then transferred into E. coli ET12567/pUZ8002 by electroporation and subsequently transferred into $S$. coelicolor M145 $\Delta g \ln A$ by conjugation. Hygromycin and apramycin resistant and kanamycin sensitive trans-conjugants were isolated from MS-plates supplemented with L-glutamine. Correct marker-less deletion of glnII was confirmed by PCR followed by sequencing as well as Southern blot analysis.

\section{Estimation of the Intracellular or Extracellular Polyamine Level Using HPLC}

Level of the intracellular polyamines was analyzed using high-performance liquid chromatography (HPLC), as described by Potter and Paton (2014). The method was modified and optimized for $S$. coelicolor. Cells were harvested by centrifugation $\left(6,000 \times g, 10 \mathrm{~min}\right.$ at $\left.4^{\circ} \mathrm{C}\right)$, washed three times in phosphate-buffered saline (PBS). The $500 \mathrm{mg}$ of the wet cells were resuspended in morpholinepropanesulfonic acid (MOPS) lysis buffer (100 mM MOPS, $50 \mathrm{mM} \mathrm{NaCl,} 20 \mathrm{mM} \mathrm{MgCl}$, $\mathrm{pH} 8.0)$ and disrupted using glass beads (150-212 $\mu \mathrm{m}$, Sigma) and a Precellys homogenizer (6500 rpm, 20 - $30 \mathrm{~s}$; Peqlab). Samples were centrifuged $\left(13,000 \times g, 10 \mathrm{~min}\right.$ at $\left.4^{\circ} \mathrm{C}\right)$, the pellet was discarded and supernatant was transferred into new tube. Trichloroacetic acid then was added to a final concentration of $10 \%$, and the mixture was incubated on ice for $5 \mathrm{~min}$. After incubation the mixture was cleared by centrifugation $(13,000 \times g$, $10 \mathrm{~min}$ at $4^{\circ} \mathrm{C}$ ), the $\mathrm{pH}$ of each sample was neutralized using $\mathrm{HCl}$ and the samples were stored at $-20^{\circ} \mathrm{C}$ until analysis. Polyamines were derivatized using pre-column derivatization with ortho-phthalaldehyde (OPA)/mercaptoethanol (MCE) (Dr. Maisch GmbH, Ammerbuch). OPA-derivatized polyamines were separated on a Reprosil OPA column $(150 \mathrm{~mm} \times 4.0 \mathrm{~mm}$, $3 \mu \mathrm{m})$ fitted with a precolumn $(10 \mathrm{~mm} \times 4 \mathrm{~mm}$, same stationary phase) (Dr. Maisch GmbH, Ammerbuch) using a HP1090 Liquid Chromatograph equipped with a diode-array detector, a thermostated autosampler and a HP Kayak XM 600 ChemStation (Agilent, Waldbronn). UV detection was performed at $340 \mathrm{~nm}$. The following gradient was used at a flow rate of $1.1 \mathrm{ml} / \mathrm{min}$ with solvent A (25 mM sodium phosphate buffer, $\mathrm{pH} 7.2$ containing $0.75 \%$ tetrahydrofuran) and solvent B [ $25 \mathrm{mM}$ sodium phosphate buffer, pH 7.2 (50\%), methanol (35\%), acetonitrile (15\%) by volume]: $t_{0}=60 \% \mathrm{~B}, t_{2.5}=70 \%, t_{12}=t_{22}=100 \% \mathrm{~B}$ (time in minutes). Cadaverine dihydrochloride, putrescine dihydrochloride, spermidine trihydrochloride, and spermine tetrahydrochloride were purchased from Sigma and used as standards. Standard solutions of polyamines were prepared with distillated water. HPLC detection limit for different polyamines was $0.1 \mathrm{mM}$. 


\section{Gene Expression Analysis by Reverse Transcriptase/PCR}

For the transcriptional analysis experiments, the $S$. coelicolor M145 wild type and the $g \ln A 3$ mutant were grown in S-medium. After 4 days, cells were washed twice with defined Evans medium

TABLE 2 | Oligonucleotides used in this study.

\begin{tabular}{|c|c|c|}
\hline Oligonucleotides & Sequences $5^{\prime}-3^{\prime}$ & Reference \\
\hline RT_hrdB1 (control) & GAGTCCGTCTCTGTCATGGCG & This work \\
\hline RT_hrdB2 (control) & TCGTCCTCGTCGGACAGCACG & This work \\
\hline RT_glnA3F & CAGGTGGAGCTGAGCGACTG & Nentwich, 201 \\
\hline RT_glnA3R & AGGCGGAGAGGTGGAGGTG & Nentwich, 201 \\
\hline RT3453F & CTGGCAGTGACCACCGTTCT & This work \\
\hline RT3453R & TGTCGGGCAGGTCCAGTTCT & This work \\
\hline RT3456F & ACCCTGGGCAACACCAGCTATC & This work \\
\hline RT3456R & AAGTGTCGTCTCCGGCGTTGTC & This work \\
\hline RT5057F & CGTCTACGGGCTGCTGTTCATC & This work \\
\hline RT5057R & GTAGTCCAGCATCGCCATCCAC & This work \\
\hline RT5651F & CAACGCGACGCCGAACTACTAC & This work \\
\hline RT5651R & GTCAACAAGGGCGATTCGGGAC & This work \\
\hline RT5655F & CAACGGCTTCTTCTACGG & This work \\
\hline RT5655R & CAGGATCTGCTCGATCTC & This work \\
\hline RT5656F & CCATCATCGAGCAGCTCCAG & This work \\
\hline RT5656R & CAGACGACCTCCACCATCAG & This work \\
\hline RT5657F & GAAGGCCCTGCTGAAGATCG & This work \\
\hline RT5657R & CGGCCATCATCATCGGGTAG & This work \\
\hline RT5658F & TCAGCCCGTCCCTGATGAAC & This work \\
\hline RT5658R & TCGCAGATCCGGTGGAAGTC & This work \\
\hline RT5666F & AACTACCCGCTCCAGATG & This work \\
\hline RT5666R & GCTGACGACGTTGATCAC & This work \\
\hline RT5667F & TCACGTACACCGAGGACATC & This work \\
\hline RT5667R & CCAGCGCCTTCTTGTTGTAG & This work \\
\hline RT5671F & GCGCCAACCAGTTCCACTAC & This work \\
\hline RT5671R & GACAGCAGGTCGAGCATCAC & This work \\
\hline RT5676F & СТТСАСССАСАССТGТТС & This work \\
\hline RT5676R & TGCTTGTACGGCATGTTC & This work \\
\hline RT5679F & AGAACGGCAAGCCCGTCAAG & This work \\
\hline RT5679R & TTGTGGGCGCACAGGTTGAG & This work \\
\hline RT5977F & TTCCAGGACGGCAACCTCAC & This work \\
\hline RT5977R & AAGACCACGCCGACGATCAG & This work \\
\hline RT6960F & ATGCCGATCCTGTACGTC & This work \\
\hline RT6960R & CGAGGTCCTTCTCCAGATG & This work \\
\hline RT6961F & TATCTCTGCGCGGTCTTC & This work \\
\hline RT6961R & AACTCGGCCAGTCCATAG & This work \\
\hline His-glnA3F & $\begin{array}{l}\text { ACATATGCATCATCATCATCATCA } \\
\text { TAGCGAGAGCGACCCCGTGCC }\end{array}$ & This work \\
\hline His-glnA3R & $\begin{array}{l}\text { AAAGCTTCAGTACTTCCAGC } \\
\text { GGTACG }\end{array}$ & This work \\
\hline glnll_hygr_P1 & $\begin{array}{l}\text { ACGTGCGCCGAGACCCACC } \\
\text { CCGAAGGATGTGGCCCCGTGA } \\
\text { TTCCGGGGATCCGTCGACC }\end{array}$ & This work \\
\hline glnll_hygr_P2 & $\begin{array}{l}\text { CCACTGACAACGCGGCCGGG } \\
\text { CGGCGGTGGCCCGGGCTCA } \\
\text { TGTAGGCTGGAGCTGCTTC }\end{array}$ & This work \\
\hline CglnA3f & ACGAATTCCCGGACGGCACAATG & This work \\
\hline CglnA3r & AGAAAGCTTGCAGGGCCTCGAAAC & This work \\
\hline
\end{tabular}

and cultivated for $24 \mathrm{~h}$ in defined Evans medium supplemented either with $25 \mathrm{mM}$ ammonium chloride or $25 \mathrm{mM}$ polyamine (cadaverine, spermidine, or putrescine). RNA isolation was performed with an RNeasy kit (Qiagen). RNA preparations were treated twice with DNase (Fermentas). First, an on-column digestion was carried out for $30 \mathrm{~min}$ at $24^{\circ} \mathrm{C}$, and afterward RNA samples were treated with DNase for $1.5 \mathrm{~h}$ at $37^{\circ} \mathrm{C}$. RNA concentrations and quality were checked using a NanoDrop ND-1000 spectrophotometer (Thermo Fisher Scientific). cDNA from $3 \mu \mathrm{g}$ RNA was generated with random nonamer primers (Sigma), reverse transcriptase and cofactors (Fermentas). PCR reactions were performed with the primers listed in Table 2. The PCR conditions were $95^{\circ} \mathrm{C}$ for $5 \mathrm{~min} ; 35$ cycles of $95^{\circ} \mathrm{C}$ for $15 \mathrm{~s}$, $55-60^{\circ} \mathrm{C}$ for $30 \mathrm{~s}$ and $72^{\circ} \mathrm{C}$ for $30 \mathrm{~s}$; and $72^{\circ} \mathrm{C}$ for $10 \mathrm{~min}$. As a positive control, $\mathrm{cDNA}$ was amplified from the major vegetative sigma factor $(h r d B)$ transcript, which is produced constitutively. To exclude DNA contamination, negative controls were carried out by using total RNA as a template for each RT-PCR.

\section{Survival Assay}

The ability of the $S$. coelicolor M145 and $\Delta g \ln A 3$ mutant to survive in the presence of polyamines was examined by the estimation of the dry weight biomass after 72 and $168 \mathrm{~h}$ of incubation in the YEME-TSB (1:1) rich complex medium. Both strains, M145 and $\triangle g \ln A 3$ mutant were inoculated into YEME-TSB supplemented with putrescine, cadaverine, spermidine as well as spermine (25 $\mathrm{mM}$ of each) and incubated for 3 days at $30^{\circ} \mathrm{C}$. As a control M145 and $\triangle g \ln A 3$ mutant were cultivated YEME:TSB without polyamines supplementation and incubated as described above. Samples $(1 \mathrm{ml})$ were taken every day and cells were harvested by centrifugation $(16,200 \times g$, $15 \mathrm{~min}$ at $4^{\circ} \mathrm{C}$ ), the residual liquid was removed and pellets were dried for $24 \mathrm{~h}$. The middle value of three technical replicated was compared with the middle value of three biological replicates and the standard error was calculated.

\section{Light Microscopy and Viability Staining}

Morphology and viability of $S$. coelicolor M145 and $\Delta g \ln A 3$ mutant cells grown in a rich complex YEME-TSB (1:1) medium was analyzed in presence of polyamines. Samples were taken from every culture after 72 and 168 h of growth, and obtained perpetrates were observed under phase-contrast microscope under $400 \times$ enlargement. To detect live and dead cells, SYTO9 and PI (propidium iodide) stains of the LIVE/DEAD BacLight Bacterial Viability Kit (Molecular Probes) were used. The SYTO 9 green fluorescent stain labels cells with intact membranes, as well as those with damaged ones. PI penetrates cells with damaged membranes, decreasing SYTO 9 stain fluorescence when both dyes are present. Thus, in the presence of both SYTO9 and PI, cells with intact cell membranes appear fluorescent green whereas cells with damaged membranes appear red. The staining solution was prepared by mixing $0.75 \mu$ l of component A and B in $500 \mu \mathrm{l}$ of water. Stained cells were analyzed by the fluorescence microscopy using Olympus BX60 microscope with an Olympus UPlanFl $100 \times$ oil objective and an Olympus BX-FLA reflected light fluorescence attachment. Images were taken with the F-view II camera (Olympus), using TxRed and eGFP filter sets for 
detection of the fluorescent markers. The ImageJ was used for image processing. Significant number of images (10) was analyzed in a minimum of three independent culture analyses.

\section{Cloning, Expression, and Purification of His-GInA3}

The gene encoding GlnA3 (SCO6962) was amplified by PCR form $S$. coelicolor genomic DNA and ligated into the expression vector pJOE2775 (Volff et al., 1996) under the control of rhamnose inducible promoter Prha. The restriction sites NdeI and HindIII were used for cloning purposes. His-GlnA3 was overexpressed in E. coli strain BL21 (DE3) using the autoinduction method for protein production (Li et al., 2011; Studier, 2014). Cells were grown initially at $37^{\circ} \mathrm{C}$ until the culture density reached an optical density of $\sim 0.6$ at $600 \mathrm{~nm}$ at which time the temperature of the shaking incubator was reduced to $20^{\circ} \mathrm{C}$. The bacterial cells were then harvested by centrifugation after $48 \mathrm{~h}$ cultivation and stored at $-20^{\circ} \mathrm{C}$ until needed. His-GlnA3 was purified by nickel ion affinity chromatography essentially as directed by the resin manufacturer (GE-Healthcare). Purified His-GlnA3 was dialyzed against $20 \mathrm{mM}$ Tris, $100 \mathrm{mM} \mathrm{NaCl}$ ( $\mathrm{pH} 8)$ and immediately used for further analysis.

\section{GInA3 In Vitro Assay and HPLC/ESI-MS Detection of the Glutamylated-product}

HPLC/ESI-MS was used to evaluate putrescine and glutamate as GlnA3 substrates and generated gamma-glutamylated putrescine as a product. Standard reactions typically contained $20 \mathrm{mM}$ HEPES ( $\mathrm{pH}$ 7.2), $150 \mathrm{mM}$ glutamate sodium monohydrate, $150 \mathrm{mM}$ putrescine dihydrochloride, $20 \mathrm{mM} \mathrm{MgCl}_{2} \times 6 \mathrm{H}_{2} \mathrm{O}$, and $10 \mathrm{mM}$ ATP were mixed with $10 \mu \mathrm{g}$ of the purified His-GlnA3 (or without GlnA3 as a control) and incubated at $30^{\circ} \mathrm{C}$ for $5 \mathrm{~min}$. The reaction was stopped by incubation of the reaction mixture at $100^{\circ} \mathrm{C}$ for $5 \mathrm{~min}$. HPLC/ESI-MS analysis of the glutamylated product generated by GlnA3 was done on an Agilent 1200 HPLC series using a Reprosil 120 C18 AQ column, $5 \mu \mathrm{m}$, $200 \mathrm{~mm} \times 2 \mathrm{~mm}$ fitted with a precolumn $10 \mathrm{~mm} \times 2 \mathrm{~mm}($ Dr. Maisch $\mathrm{GmbH}$, Ammerbuch, Germany) coupled to an Agilent LC/MSD Ultra Trap System XCT 6330 (Agilent, Waldbronn, Germany). Analysis was carried out using $0.1 \%$ formic acid as solvent $\mathrm{A}$ and acetonitrile with $0.06 \%$ formic acid as solvent $\mathrm{B}$ at a flow rate of $0.4 \mathrm{ml} \mathrm{min}{ }^{-1}$. The gradient was as follows: $t_{0}=t_{5}=0 \% \mathrm{~B}, t_{20}=40 \% \mathrm{~B}$ (time in minutes). Injection volume was $2.5 \mu \mathrm{l}$, column temperature was $40^{\circ} \mathrm{C}$. ESI ionization was done in positive mode with a capillary voltage of $3.5 \mathrm{kV}$ and a drying gas temperature of $350^{\circ} \mathrm{C}$.

\section{RESULTS}

\section{GInA2, GInA3, and GInA4 Annotated as GSI-Like Do Not Have a Glutamine Synthase Function in S. coelicolor M145}

In order to determine whether $\mathrm{Gln} A 2, \mathrm{Gln} A 3$, and $\mathrm{Gln} A 4$ were involved or not involved in glutamine biosynthesis in S. coelicolor M145, single and double mutants of genes $g \ln A$ and $g \ln I I$ encoding proven GSs, GSI and GSII, respectively, were deleted in the parental strain M145. REDIRECT gene-replacement procedure (Gust et al., 2003) was employed to delete $g \ln I I$ gene (SCO2210) in a previously generated $\Delta g \ln A$ mutant (Fink et al., 1999) as described in Section "Materials and Methods." Independent clones of the single $\Delta g \ln A$ and $\Delta g \ln I I$ mutants, of the double $\Delta g \ln A \Delta g \ln I I$ mutant and of the parental strain M145 were tested for their ability to grow on defined Evans-agar supplemented with ammonium chloride $(50 \mathrm{mM})$ as sole nitrogen source. Glutamine synthetases, GSI and GSII catalyze condensation of L-glutamate and ammonia to form L-glutamine in the ATP dependent reaction. Consequently, growth reveals the ability of the strains to assimilate ammonium and to synthesize glutamine whereas absence of growth indicates absence of this ability. S. coelicolor M145 and the single deletion mutants, $\Delta g \ln A$ and $\Delta g \ln I$, were able to grow on the plates, demonstrating that both $g \ln A$ and $g \ln I I$ encode functional GSs as reported previously (Reuther and Wohlleben, 2007). In contrast, the $\Delta g \ln A \Delta g \ln I I$ double mutant was unable to grow on this medium (Figure 2) and was auxotrophic for glutamine. Addition of L-glutamine restored growth of the $\Delta g \ln A \Delta g \ln I I$ double mutant on this medium. These results indicated that $\mathrm{G} \ln \mathrm{A} 2, \mathrm{G} \ln \mathrm{A} 3$, and $\mathrm{G} \ln \mathrm{A} 4$ do not have a GS function that can substitute for that of GSI and GSII and avoid glutamine auxotrophy.

\section{The Deletion of GInA3, But Not that of GInA2 and GInA4 Abolished Polyamine Utilization}

In an attempt to decipher the function of GS-like enzymes, the genes $g \ln A 2, g \ln A 3$, and $g \ln A 4$ were deleted in the parental strain S. coelicolor M145. The $\Delta g \ln A 2$ (Nentwich, 2010), $\Delta g \ln A 3$ (Rexer et al., 2006), and the $\Delta g \ln A 4$ (this work) mutants were tested for their ability to utilize different nitrogen sources. Phenotypic analysis was performed on defined Evans-agar supplemented with the following sole nitrogen sources: ammonium chloride, sodium nitrate, monosodium L-glutamate, L-glutamine, putrescine dihydrochloride, cadaverine dihydrochloride, spermidine trihydrochloride, and spermine tetrahydrochloride. Growth and morphology of the parental strain M145 and the $\Delta g \ln A 2, \Delta g \ln A 3$, and $\Delta g \ln A 4$ mutants were monitored on defined Evans-agar after 3 to 12 days of incubation at $30^{\circ} \mathrm{C}$. Remarkably, S. coelicolor M145 could grow on all tested nitrogen sources (Figure 3). Interestingly, growth of the $S$. coelicolor M145 on polyamines resulted in delayed aerial mycelium and spore formation as well as abolition of actinorhodin (blue antibiotic) and enhanced prodigiosin (red antibiotic) production (Figure 3). Growth of the $g \ln A 2, g \ln A 3$, and $g \ln A 4$ mutants was similar to that of the parental strain in the presence of ammonium chloride, sodium nitrate, L-glutamine, and monosodium L-glutamate. Growth of the $g \ln A 3$ mutant, but not that of the $g \ln A 2$ and $g \ln A 4$ mutants, was inhibited in the presence of putrescine, cadaverine, spermidine, and spermine (Figure 3). The complementation of the $g \ln A 3$ mutant by the $g \ln A 3$ gene under control of the constitutive promoter (PermE) restored the growth of this mutant on polyamine plates (Supplementary Figure S1). Altogether these results indicated 

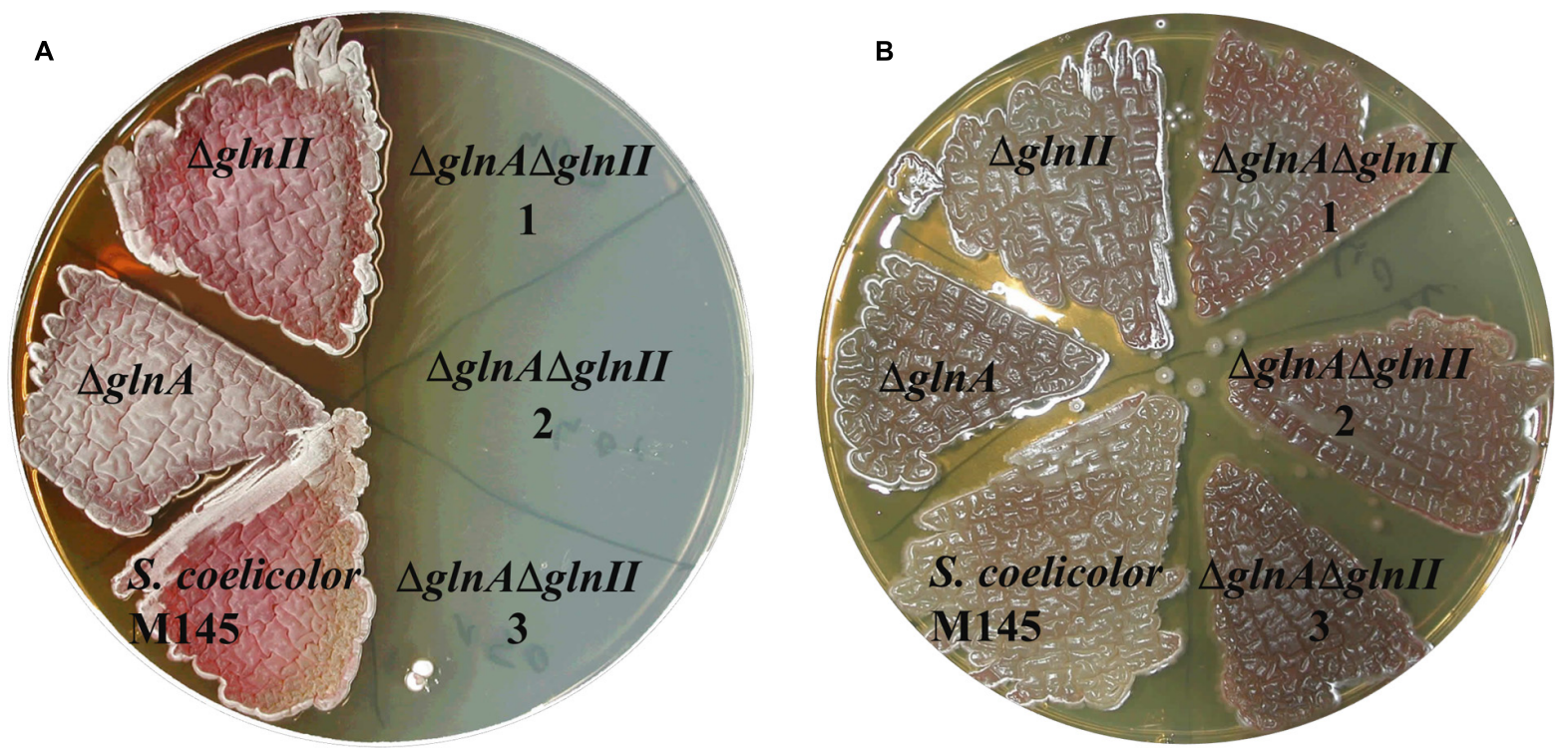

FIGURE 2 | Phenotypic analysis of parental strain S. coelicolor M145 and mutants: $\Delta g I n A, \Delta g I n I$ and $\Delta g / n A \Delta g I n I I(1,2,3-$ independent clones) on defined Evans medium supplemented with 50 mM ammonium chloride (A) or with $50 \mathrm{mM}$ ammonium chloride and $50 \mathrm{mM}$ L-glutamine (B). Deletion of both genes, glnA and glnll, for GSs, resulted in a glutamine auxotrophic phenotype indicating that GlnA2, GlnA3, and GlnA4 were incapable to substitute GSI and GSII metabolic function in the cell.

that the disruption of $g \ln A 3$, but not that of $g \ln A 2$ and $g \ln A 4$, completely abolished the utilization of polyamines as a nitrogen source. GlnA2 and GlnA4 have obviously a function different from that of GlnA3 since their deletion did not influence polyamine utilization. Interestingly, the $g \ln A 3$ mutant showed defect in formation of aerial mycelium as well as sporulation on defined medium supplemented with glutamate (50 mM). Moreover, enhanced actinorhodin and prodigiosin production was observed on the nitrate, glutamine and ammonium plates, respectively (Figure 3), indicating an impact of $g \ln A 3$ deletion on the secondary metabolites production and morphological differentiation in S. coelicolor.

\section{Expression of $g$ InA3 Is Induced by Polyamines and Starvation Conditions}

Reverse transcription/PCR experiments were performed as described in Section "Materials and Methods" to determine whether $g \ln A 3$ expression was influenced by $N$ - and/or $C$-concentrations as reported for $g \ln A$ and $g \ln I I$ (Amin et al., 2016) as well as to investigate the expression of $g \ln A 3$ in the presence of polyamines. For this purpose, parental strain M145 was grown in complex S-medium subsequently transferred into defined Evans medium supplemented either with polyamines (25 $\mathrm{mM})$ or ammonium chloride $(25 \mathrm{mM})$ as a sole nitrogen source. Total RNA isolated after $24 \mathrm{~h}$ from S. coelicolor M145 was used to generate cDNA. Subsequently, reverse transcription/PCR analysis was performed using primers internal to $g \ln A 3$. HrdB, encoding the main sigma factor of RNA polymerase, that has relatively constant levels of expression throughout growth (Buttner et al., 1990) was used as internal control. Expression of genes encoding GSs, $g \ln A$ and $g \ln I I$, was shown to be strongly enhanced in condition of ammonium limitation and reduced or completely abolished in condition of ammonium proficiency in $S$. coelicolor, irrespective of the glucose concentration (Amin et al., 2016). Interestingly, the expression of $g \ln A 3$ was also strongly enhanced under ammonium limitation, but only in combination with low glucose concentration suggesting that its expression does not require polyamines. Furthermore, transcriptional analysis of $g \ln A 3$ revealed strong induction of the expression of this gene in the presence of putrescine, cadaverine and spermidine (Figure 4), putative substrates of the encoded enzyme.

\section{Transcriptional Analysis-Based Identification of Orthologs of the Putative Polyamine Transport and Polyamine Utilization Genes in S. coelicolor M145}

Polyamine uptake and utilization pathways are largely uncharacterized in streptomycetes. BlastP analysis was used to predict uptake systems and putative enzymes involved in polyamine utilization in $S$. coelicolor, whose amino acid sequences are closely related to the amino acid sequences of the characterized proteins from E. coli and P. aeruginosa (Kusano and Suzuki, 2015). Similarity based prediction revealed 18 strong homologs in S. coelicolor (genome accession number AL645882). Their amino acid identities ranged from 24 to 50\%, while their similarities ranged from 41 to $65 \%$ (Figure 5). To demonstrate that these genes were induced by polyamines, their expression patterns were analyzed in the presence of putrescine, cadaverine, and spermidine as sole $N$-source as well as ammonium as control. 

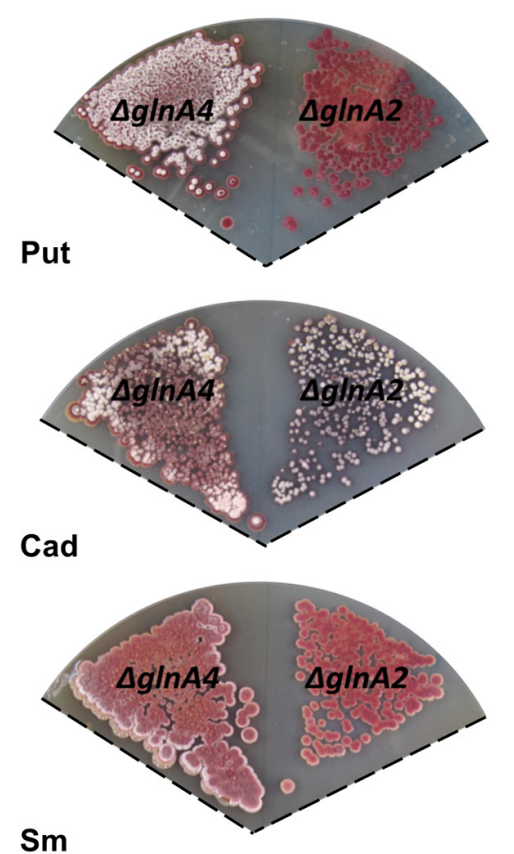

Sm

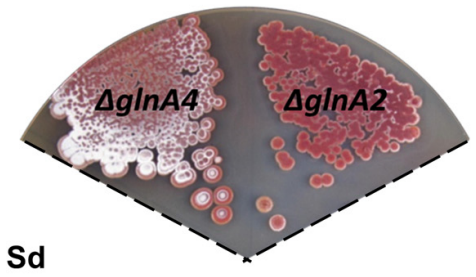

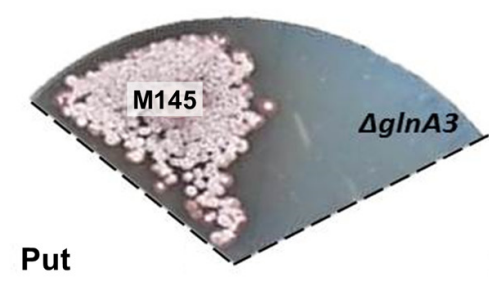

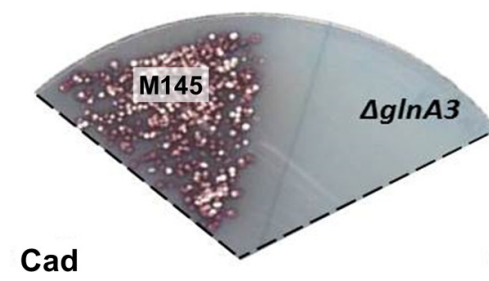

Glu
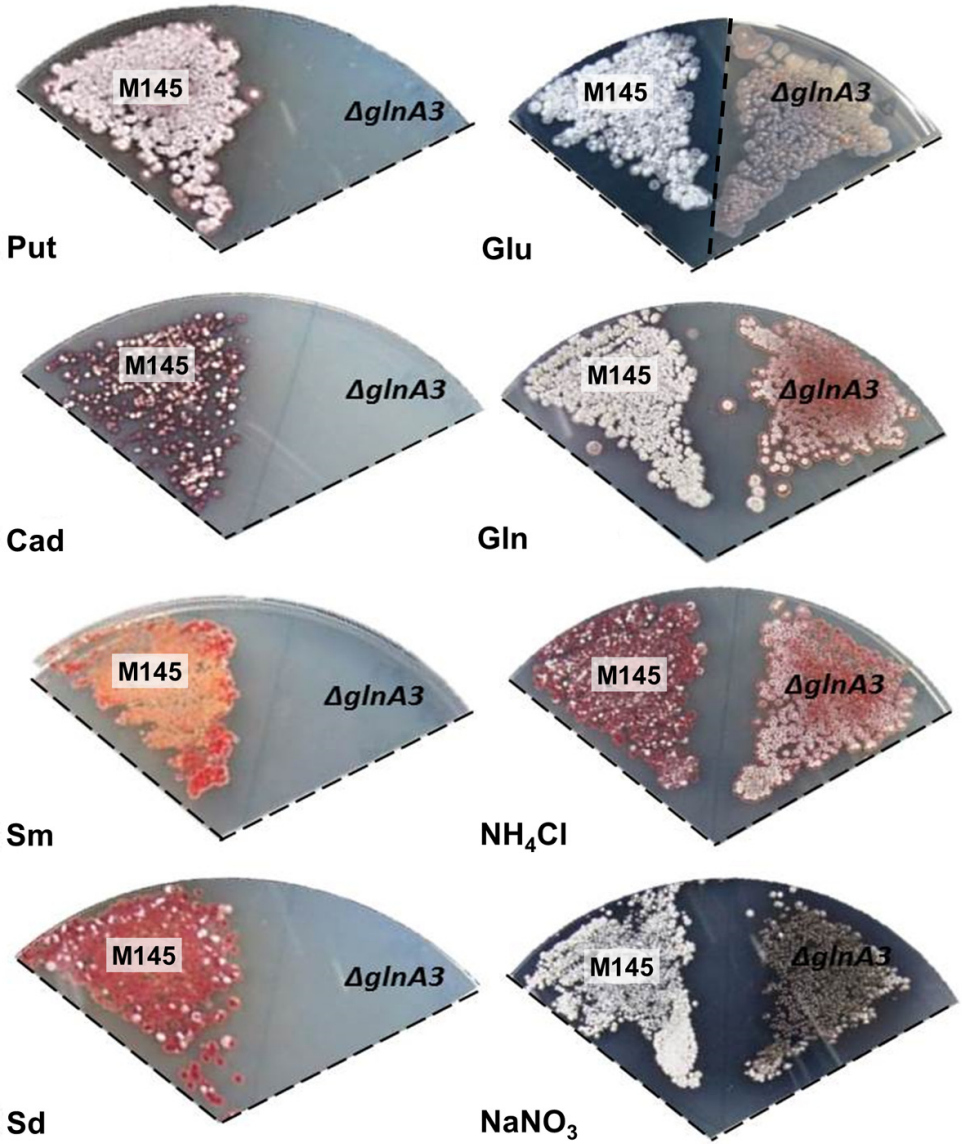

FIGURE 3 | Physiological role of the glnA3 gene product in S. coelicolor M145 cells grown in the presence of polyamines. (A) Phenotypic comparison of parental strain S. coelicolor M145 and $\Delta g \ln A 2, \Delta g \ln A 3$, and $\Delta$ glnA4 mutants grown on defined Evans medium supplemented with Put - putrescine dihydrochloride (200 mM), Cad - cadaverine dihydrochloride (50 mM), Sm - spermine tetrahydrochloride (25 mM), Sd - spermidine trihydrochloride (25 mM) as well as on Glu - monosodium glutamate $(50 \mathrm{mM})$, Gln - glutamine $(50 \mathrm{mM}), \mathrm{NH}_{4} \mathrm{Cl}$ - ammonium chloride $(50 \mathrm{mM})$ and $\mathrm{NaNO}_{3}-\mathrm{sodium}$ nitrate $(50 \mathrm{mM})$ as sole nitrogen source. Each panel represents observations on a single agar plate, except the phenotypic analysis of the glnA3 mutant and parental strain in the presence of glutamate has been documented on two separate agar plates as indicated by the dotted line. Deletion of glnA3 resulted in the no-growth phenotype in the presence of high polyamine concentrations.

Analysis of the $g \ln A 3$ genomic region revealed two genes SCO6960 and SCO6961 located downstream of glnA3 and likely co-transcribed with the latter. SCO6961 encodes an uncharacterized protein belonging to the amidohydrolase 2 family, whereas SCO6960 encodes a small protein of unknown function conserved among streptomycetes. However, no orthologs of these genes could be found in E. coli and $P$. aeruginosa, suggesting that the polyamine utilization pathway might be different in S. coelicolor. Transcriptional analysis of the SCO6960 and SCO6961 indicated that the expression of these genes was inducible by polyamine as that of $g \ln A 3$ (Figure 5). In contrast, the expression of the genes SCO6963, SCO6964, and SCO6965 located upstream of this putative operon and encoding uncharacterized lipoprotein and two small proteins of unknown function were not induced in conditions of ammonium limitation nor in the presence of polyamine (data not shown).

Furthermore, BlastP analysis predicted two $\mathrm{ABC}$ transporters and two permeases potentially involved in the uptake of polyamines. The SCO5667-70 and SCO3453-56 predicted gene products resemble the $\mathrm{ABC}$ transport systems PotFGHI or SpuEFGH from E. coli and $P$. aeruginosa, respectively. The expression of these genes was only weakly inducible in the presence of polyamines (Figure 5). In contrast, the expression of the genes encoding the putative polyamine permeases SCO5057 and SCO5977 was strongly induced in the presence of all polyamines or only putrescine, respectively (Figure 5). The expression of SCO5658 (encoding predicted polyamine binding protein) was strongly induced in the presence of spermidine (Figure 5).

Prediction of genes encoding enzymes involved in the post-glutamylation steps in S. coelicolor revealed orthologs for gamma-glutamylpolyamine oxidoreductase (SCO5671), polyamine-pyruvate/2-oxoglutarate transaminase (SCO5655) as well as close orthologs of (gamma-glutamyl-) gammaaminobutyraldehyde dehydrogenases PatD and PuuC (SCO5657 and SCO5666) and SCO5676 encoding predicted GabT-like 


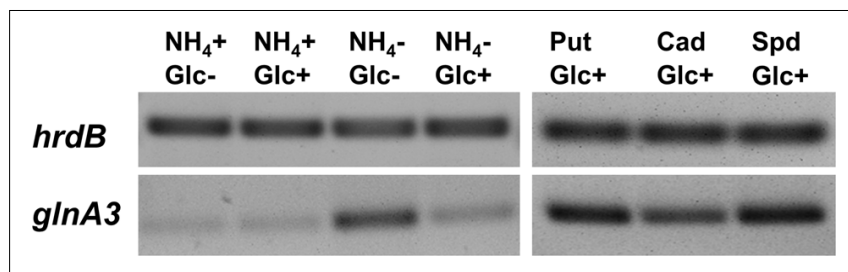

FIGURE 4 | Transcriptional analysis of gInA3 in the presence of polyamines and ammonium as a sole nitrogen sources. Reverse transcriptase/PCR of glnA3 and hrdB (control) from S. coelicolor M145 cultivated in defined Evans medium with low $(5 \mathrm{mM})$ or high $(50 \mathrm{mM})$ concentrations of ammonium chloride or polyamines (Put - putrescine; Cad - cadaverine and Spd - spermidine, $25 \mathrm{mM}$ of each) and glucose as a sole carbon source high Glc+ (25 g/l) or low Glc- (2.5 g/l). Total RNA was isolated from mycelium harvested after $24 \mathrm{~h}$ of cultivation in the defined Evans medium.

gamma-aminobutyrate transaminase and finally SCO5676, encoding predicted succinate semialdehyde dehydrogenase (GabD-like). The expression of all these genes (except SCO5671) was strongly induced in the presence of polyamines (Figure 5). Altogether, putative homologs of genes encoding predicted polyamine uptake systems and proteins involved in the polyamine utilization in $S$. coelicolor showed enhanced expression in the presence of polyamines whereas their expression was abolished in the presence of ammonium. To summarize, the search for proteins orthologs of those involved in the catabolism of polyamine in other bacteria using BlastP and the analysis of gene expression patterns, led us to predict, so far unknown, polyamine degradation pathway in $S$. coelicolor (Figure 1).

\section{GInA3 Deletion Mutant Accumulates Polyamines Intracellularly}

In an attempt to understand the basis of polyamine toxicity in the $g \ln A 3$ mutant grown in the presence of polyamine, the intracellular polyamine content of S. coelicolor M145 and $g \ln A 3$ mutant was analyzed by HPLC. To do so, the parental strain M145 and the $g \ln A 3$ deletion mutant were cultivated in a complex S-medium for 4 days at $30^{\circ} \mathrm{C}$. Cells were harvested and washed with Evans medium without $N$-source to remove remaining complex $N$-sources. Washed cells were transferred into defined Evans medium containing polyamines as a sole $N$-source and incubated at $30^{\circ} \mathrm{C}$ for further 4 days. Samples for the biomass determination and extraction of intracellular polyamines were collected every day. Cell pellets and supernatants were used to extract intracellular and extracellular polyamines, respectively. Comparison of intracellular polyamine levels of both strains revealed three, six and twenty fold higher levels of putrescine, cadaverine, and spermidine in $\triangle g \ln A 3$ mutant, respectively (Figure 6) than in the parental strain after 4 days of cultivation. The intracellular concentration of polyamines decreased over time in the parental strain M145, but not in the mutant strain. After 4 days of cultivation, intracellular polyamine concentrations ranged between 0.5 and $0.7 \mu \mathrm{mol} / \mathrm{g}$ of biomass, whereas that of the $g \ln A 3$ mutant ranged between 3.1 and $5.1 \mu \mathrm{mol} / \mathrm{g}$. Furthermore, comparison of extracellular polyamine levels in the parental strain culture and $g \ln A 3$ culture revealed strong differences. The residual level of polyamines in the $g \ln A 3$ mutant culture supernatant remained high from the first to the fourth day of incubation (Figure 7), whereas after 4 days of incubation no peak for polyamines could be detected in the culture supernatant of the parental strain. Altogether, these data indicated that the $g \ln A 3$ mutant was able to uptake polyamines, but was unable to degrade them. The absence of polyamine degradation in the $g \ln A 3$ mutant obviously resulted in high concentration of intracellular polyamine, likely to be responsible for the inhibition of further uptake of external polyamines (Figure 7).

\section{The $\Delta g \ln A 3$ Mutant Grown in Complex Medium with Polyamines Showed Atypical Mycelial Morphology and Short Lifetime Span}

The $\Delta g \ln A 3$ mutant and its parental strain S. coelicolor M145 were cultivated in a rich complex liquid medium (YEME:TSB) supplemented or not (control) with polyamines (putrescine, cadaverine, spermidine, and spermine, $25 \mathrm{mM}$ of each). Biomass yields as well as morphology of both strains were monitored over 7 days. The $\Delta g \ln A 3$ mutant yielded significantly lower biomass than the parental strain after 72 and $168 \mathrm{~h}$ of cultivation in the complex medium supplemented with polyamines (Figure 8). Prolonged incubation of the $\Delta g \ln A 3$ mutant culture did not result in any significant biomass increase. In this medium, S. coelicolor M145 showed its typical pellet growth whereas growth of the $\triangle g \ln A 3$ mutant was dispersed. This indicated that despite the presence of alternative nitrogen sources in this complex medium, besides polyamines, growth of $\Delta g \ln A 3$ mutant was impaired most likely because of intracellular accumulation of polyamines.

The mycelium of the $\Delta g \ln A 3$ mutant grown in the complex medium with polyamines was observed under microscope. After 3 days of cultivation, the parental strain formed a long and compact, branched mycelium constituting pellets whereas the $\Delta g \ln A 3$ mutant formed non-branched mycelium (Figure 9). The mycelial fragments of the $\Delta g \ln A 3$ mutant were significantly shorter and thicker than those of the parental strain M145 after 3 or 7 days of cultivation in the medium containing polyamines (Figure 10).

In order to assess more precisely the toxic effect of polyamines, the viability of the $\Delta g \ln A 3$ mutant was assessed with SYTO9/PI staining. The SYTO 9 green fluorescent stain labels all cells, whereas PI penetrates only cells with damaged membranes, decreasing SYTO 9 stain fluorescence when both dyes are present. In the presence of both, SYTO9 and PI, cells with intact cell membranes appear fluorescent green and dead cells with damaged membranes appear red. Whereas the parental strain M145 appeared green (alive) in the presence of polyamines, most filaments in the culture of the $\Delta g \ln A 3$ mutant were red (dead) after 7 days of incubation (Figure 9). These results demonstrated that the absence of GlnA3 led to the toxic accumulation of polyamine that impaired growth and viability and suggested that GlnA3 plays a major role in polyamine degradation. 


\begin{tabular}{|c|c|c|c|c|c|c|c|}
\hline $\begin{array}{l}\text { Gene } \\
\text { /protein } \\
\text { (acc. no.) }\end{array}$ & $\begin{array}{l}\text { Expre } \\
\text { Put }\end{array}$ & $\begin{array}{l}\text { ssion p } \\
\text { Cad }\end{array}$ & $\begin{array}{l}\text { attern } \\
\text { Sd }\end{array}$ & $\mathrm{Am}$ & Predicted function of the encoded protein & $\begin{array}{l}\text { Homologues in E.coli } \\
\text { identity/similarity [\%] }\end{array}$ & $\begin{array}{l}\text { Homologues in P. aeruginosa } \\
\text { identity/similarity [\%] }\end{array}$ \\
\hline \multicolumn{8}{|l|}{ hrdB } \\
\hline SCO3453 & E & & & & $\begin{array}{l}\text { polyamine ABC transporter ATP-binding } \\
\text { protein PotA-like }\end{array}$ & $\begin{array}{l}\text { PotA (b1126): } 43 / 59 \\
\text { YdcT(b1441): } 38 / 55\end{array}$ & $\begin{array}{l}\text { PA0603: 41/55 } \\
\text { PA0326: } 37 / 51\end{array}$ \\
\hline SCO3454 & n.d. & & & & $\begin{array}{l}\text { polyamine } \mathrm{ABC} \text { transporter - membrane } \\
\text { protein PotC-like }\end{array}$ & $\begin{array}{l}\text { PotC (b1124): } 27 / 49 \\
\text { YdcV(b1443): } 27 / 44\end{array}$ & $\begin{array}{l}\text { PA0324: 37/51 } \\
\text { PotC (PA3609): 29/51 }\end{array}$ \\
\hline SCO3455 & n.d. & & & & polyamine $\mathrm{ABC}$ transport protein & $\begin{array}{l}\text { PotB(b1125): } 24 / 41 \\
\text { YdcU(b1442): } 27 / 42\end{array}$ & $\begin{array}{l}\text { PotB (PA0205): } 34 / 45 \\
\text { PA3252: } 26 / 44\end{array}$ \\
\hline SCO3456 & e. & & & & $\begin{array}{l}\text { polyamine } \mathrm{ABC} \text { transporter - substrate } \\
\text { binding protein }\end{array}$ & YnjB (b1754): $37 / 55$ & PA0203: $26 / 47$ \\
\hline SCO5057 & 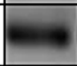 & Enos & $=$ & & amino acid /polyamine permease & $\begin{array}{l}\text { PuuP (b1296): 29/48 } \\
\text { PlaP (b2014): 28/47 }\end{array}$ & PA5510: $42 / 59$ \\
\hline SCO5651 & 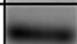 & & & & lysine/ornithine decarboxylase like enzyme & - & - \\
\hline SCO5655 & E. & & & & $\begin{array}{l}\text { alpha ketoglutarate/pyruvate-polyamine } \\
\text { aminotransferase }\end{array}$ & PatA (b3073): 32/47 & SpuC (PA0299): 36/56 \\
\hline SCO5656 & & & 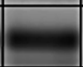 & & $\begin{array}{l}\text { Lrp/AsnC family transcriptional regulator, } \\
\text { unknown function }\end{array}$ & - & - \\
\hline$S C 05657$ & 2 & & 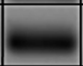 & & $\begin{array}{l}\text { gamma-aminobutyraldehyde } \\
\text { dehydrogenase }\end{array}$ & $\begin{array}{l}\text { PatD (b1444): 50/65 } \\
\text { PuuC (b1300):36/54 }\end{array}$ & $\begin{array}{l}\text { BetB (PA5373): 40/57 } \\
\text { PA0219: } 37 / 54\end{array}$ \\
\hline$S C O 5658$ & 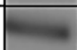 & & 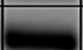 & & polyamine-binding lipoprotein & PotF (b0854): 29/47 & SpuD(PA0300): 29/48 \\
\hline SCO5666 & & & & & $\begin{array}{l}\text { gamma-aminobutyraldehyde } \\
\text { dehydrogenase }\end{array}$ & $\begin{array}{l}\text { PatD (b1444): } 49 / 65 \\
\text { PuuC (b1300):36/57 }\end{array}$ & PauC (PA5312):36/56 \\
\hline$S C O 5667$ & & & & & $\begin{array}{l}\text { polyamine } A B C \text { transporter substrate- } \\
\text { binding protein }\end{array}$ & PotF (b0854): 29/47 & SpuE (PA0301): 28/46 \\
\hline$S C 05668$ & n.d. & & & & $\begin{array}{l}\text { polyamine } A B C \text { transporter substrate- } \\
\text { binding protein }\end{array}$ & PotG (b0855): 45/62 & SpuF (PA0302): 42/60 \\
\hline SCO5669 & n.d. & & & & $\begin{array}{l}\text { polyamine } \mathrm{ABC} \text {-transporter integral } \\
\text { membrane protein }\end{array}$ & PotH (b0856): 40/61 & SpuG (PA0303): 39/60 \\
\hline SCO5670 & n.d. & & & & $\begin{array}{l}\text { polyamine } A B C \text {-transporter integral } \\
\text { membrane protein }\end{array}$ & Potl (b0857): $35 / 53$ & SpuH (PA0304): 36/55 \\
\hline$S C 05671$ & & & & & $\begin{array}{l}\text { gamma-glutamyl-polyamine } \\
\text { oxidoreductase }\end{array}$ & PuuB (b1301): 32/45 & PauB3(PA2776): 31/46 \\
\hline SCO5676 & $\mathbf{0}$ & & $=$ & & $\begin{array}{l}\text { gamma-aminobutyrate aminotransferase } \\
\text { gabT-like or puuE-like }\end{array}$ & $\begin{array}{l}\text { GabT (b2662): 46/60 } \\
\text { PuuE (b1302): 44/58 }\end{array}$ & GabT (PA0266): 43/59 \\
\hline SCO5679 & & & $=$ & & $\begin{array}{l}\text { succinate-semialdehyde dehydrogenase } \\
\text { gabD-like }\end{array}$ & GabD (b2661): 34/52 & GabD (PA0265): 34/51 \\
\hline SCO5977 & 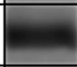 & & & & amino acids /polyamine permease & PuuP (b1296): 27/43 & $\begin{array}{l}\text { PA5510: } 27 / 46 \\
\text { PA0322: } 30 / 47\end{array}$ \\
\hline$S C 06960$ & & & $=$ & & hydrolase & - & - \\
\hline SCO6961 & & & & & amidohydrolase & - & - \\
\hline SCO6962 & & & & & $\begin{array}{l}\text { putative gamma- } \\
\text { glutamyl-polyamine synthetase GInA3 }\end{array}$ & PuuA (b1297): 24/42 & $\begin{array}{l}\text { PauA7(PA5508): } 36 / 48 \\
\text { Spul (PA0296): } 26 / 41\end{array}$ \\
\hline
\end{tabular}

FIGURE 5 | Transcriptional analyses of putative gene homologs encoding predicted proteins involved in polyamine degradation in S. coelicolor. Reverse transcriptase/PCR of genes and hrdB (control) from S. coelicolor M145 cultivated in defined Evans medium with polyamines (Put - putrescine; Cad - cadaverine or Spd - spermidine, $25 \mathrm{mM}$ of each) and glucose as a sole carbon source Glc ( $25 \mathrm{~g} / \mathrm{l})$. Total RNA was isolated from mycelium harvested after $24 \mathrm{~h}$ of cultivation in the defined Evans medium.

\section{GInA3 a Predicted Gamma-Glutamylpolyamine Synthetase in S. coelicolor M145}

The GlnA3 protein belongs to large class of ligases which form carbon-nitrogen bonds using energy from ATP (class 6.3.1). This class contains twenty different subclasses of enzymes including GS (class 6.3.1.2), glutamate - ethylamine ligase (class 6.3.1.6) and glutamate-putrescine ligase (6.3.1.11). GlnA3 protein sequence analysis by InterProScan ${ }^{1}$ predicted two enzymatic

\footnotetext{
${ }^{1}$ http://www.ebi.ac.uk/interpro
}

domains: N-terminal GS, beta-Grasp domain (IPR008147) and the C-terminal catalytic domain of GS (IPR008146). Searching for functionally and structurally characterized GlnA3 homologs from the Protein Data Bank (PDB) revealed a gamma-glutamylmonoamine/polyamine synthetase PauA7 (PA5508) as a likely. PauA7 is involved in monoamine/polyamine gamma-glutamylation in P. aeruginosa (Ladner et al., 2012). The available crystal structure of Pau7 (Protein Data Bank entry: 4HPP) and GS GSI ${ }_{S t}$ from S. typhimurium (Protein Data Bank entry: 1FPY) were used as the templates to generate a structural identical conserved binding residues for glutamate 

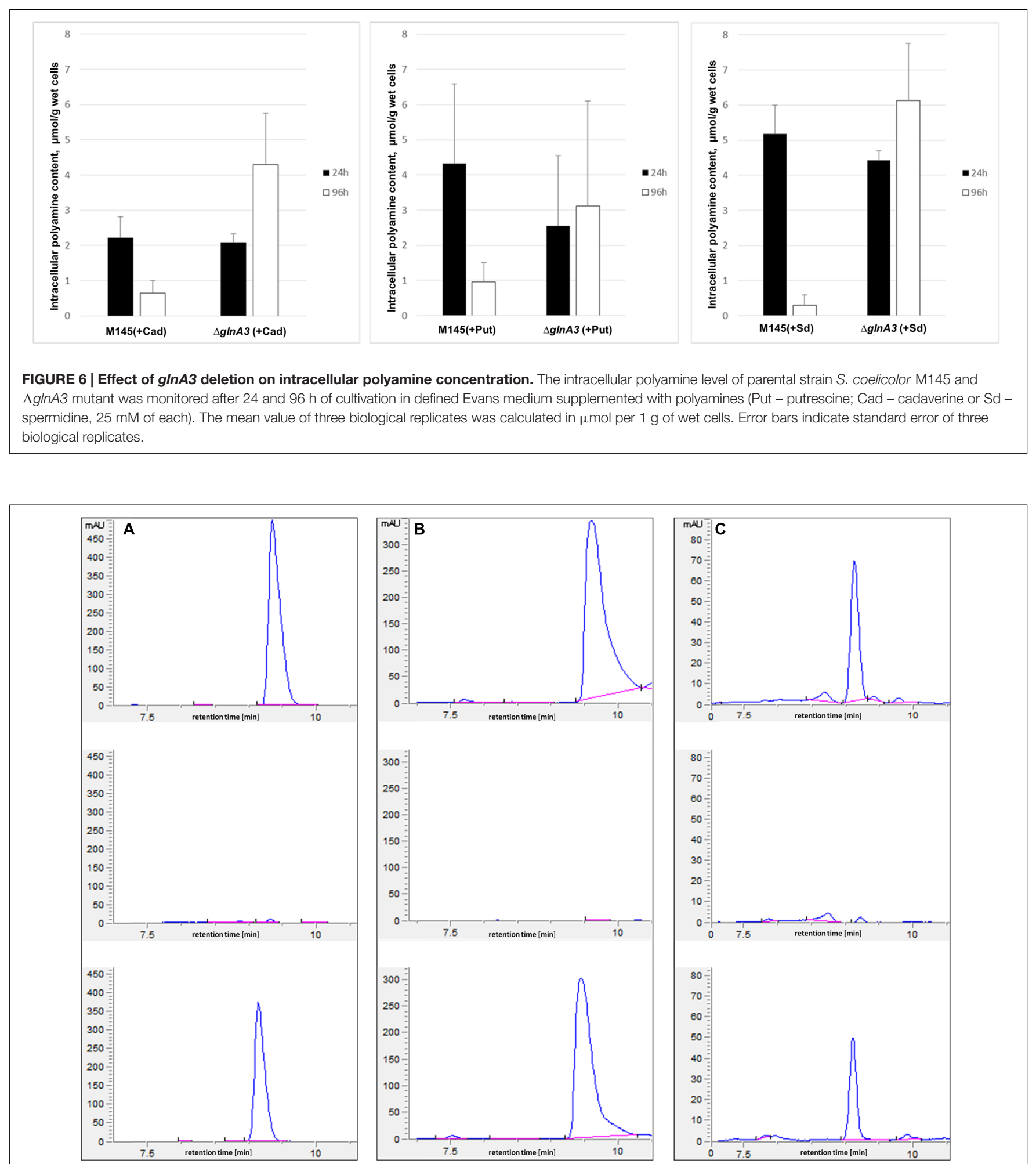

FIGURE 7 | HPLC-based detection of polyamines in supernatant from the $96 \mathrm{~h}$ culture of parental strain M145 and $\Delta g$ InA3 mutant. Both strains were grown in defined Evans medium supplemented with either (A) putrescine $(25 \mathrm{mM})$, (B) cadaverine (25 mM) or (C) spermidine (25 mM). Upper HPLC chromatogram: polyamine standard, middle HPLC chromatogram: detection of polyamines remained in the supernatant of the M145 culture, lower HPLC chromatogram: detection of polyamines remained in the supernatant of the $\triangle g l n A 3$ mutant culture. Results indicate that only parental strain $S$. coelicolor M145 was able to completely utilize whole polyamines from the medium after $96 \mathrm{~h}$ of incubation. 


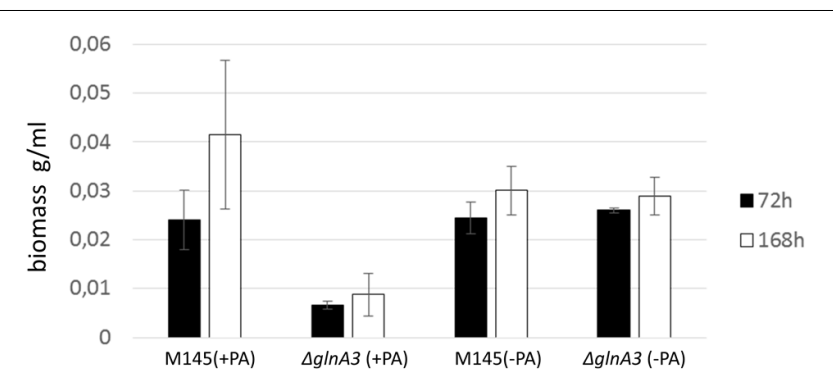

FIGURE 8 | Effect of the gInA3 deletion on a biomass accumulation in a rich complex medium supplemented with and without polyamines. Monitoring of changes in biomass accumulation of the parental strain

S. coelicolor M145 and $\Delta$ glnA3 mutant in the YEME:TSB (1:1) medium supplemented with polyamines total concentration $100 \mathrm{mM}$ (putrescine, cadaverine, spermidine, and spermine, $25 \mathrm{mM}$ of each) after 72 and $168 \mathrm{~h}$ of incubation. Error bars indicate standard error of three biological replicates.

and ATP as well as two divalent metal ions $\left(\mathrm{Mg}^{++} / \mathrm{Mn}^{++}\right)$. However, the binding pocket for ammonium and monoamine differ significantly. The GSI (as $_{\text {(all }}$ as other eukaryotic and bacterial GS) and the PauA7 require two divalent metal ions per one subunit for activity. These ions have a structural as well as a catalytic role. Comparison of the conserved catalytic residues for the binding of divalent metal ions revealed four conserved glutamate residues E151, E153, E207, E214 and one conserved histidine residue $\mathrm{H} 263$ in the GlnA3 model structure (corresponding to E131, E133, E180, E187, and H236 in PauA7, as

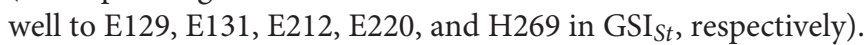
Moreover, three conserved residues involved in coordination of the glutamate binding in GSI $_{S t}$ and PauA7, were found in the
GlnA3 model structure. These GlnA3 residues (N260, G261, and R316) correspond to the N233, 258 G234, and R290 in PauA7 as

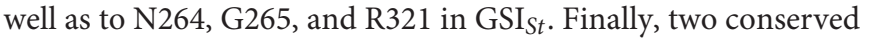
residues ( $\mathrm{H} 265$ and $\mathrm{R} 339$ both corresponding to $\mathrm{H} 271$ und R344 in $\mathrm{GSI}_{S t}$ ) important for coordination of the beta-phosphate and alpha-phosphate group of ADP were found in the GlnA3 model. This comparative in silico analysis demonstrates that GlnA3 possess conserved residues for binding of two metal ions, L-glutamate and ATP (Supplementary Figure S2). An essential element of $\mathrm{GSI}_{S t}$ catalytic pocket is a loop, termed "the E327 flap" $\left(\mathrm{GSI}_{S t}\right)$. The GSI active site is located between two subunits, and the E327-flap closes the catalytic site by interaction of the E335 with D50 from an adjacent subunit within the same ring, shielding the $\gamma$-glutamyl phosphate intermediate from hydrolysis. The second conserved residue D50 is involved in the deprotonation of ammonium for attack on the $\gamma$-glutamyl phosphate. Interestingly, these key acidic residues (E327 and D50) essential for the catalytic synthesis of glutamine in $\mathrm{GSI}_{S t}$ are not conserved in PauA7 nor in GlnA3 (Supplementary Figure S2). In PauA7 structure and GlnA3 model these loops are much bigger and instead E327, a non-polar W327 residue occupies analogous position in the GlnA3 model structure (corresponding to W296 in PauA7). The conserved residue D50 that increases the affinity for ammonium binding in $\mathrm{GSI}_{S t}$ is replaced by G40 and G63 in PauA7 and $273 \mathrm{GlnA3}$, respectively. Moreover, the conserved Y179 in $\mathrm{GSI}_{S t}$ that coordinates the ammonium binding pocket is substituted by A147 in PauA7 and A169 in GlnA3, providing much more space for a bulky substrate such as polyamine (Supplementary Figure S2). The significant overall similarity of GlnA3 to the gamma-glutamylmonoamine/polyamine synthetase PauA7, the
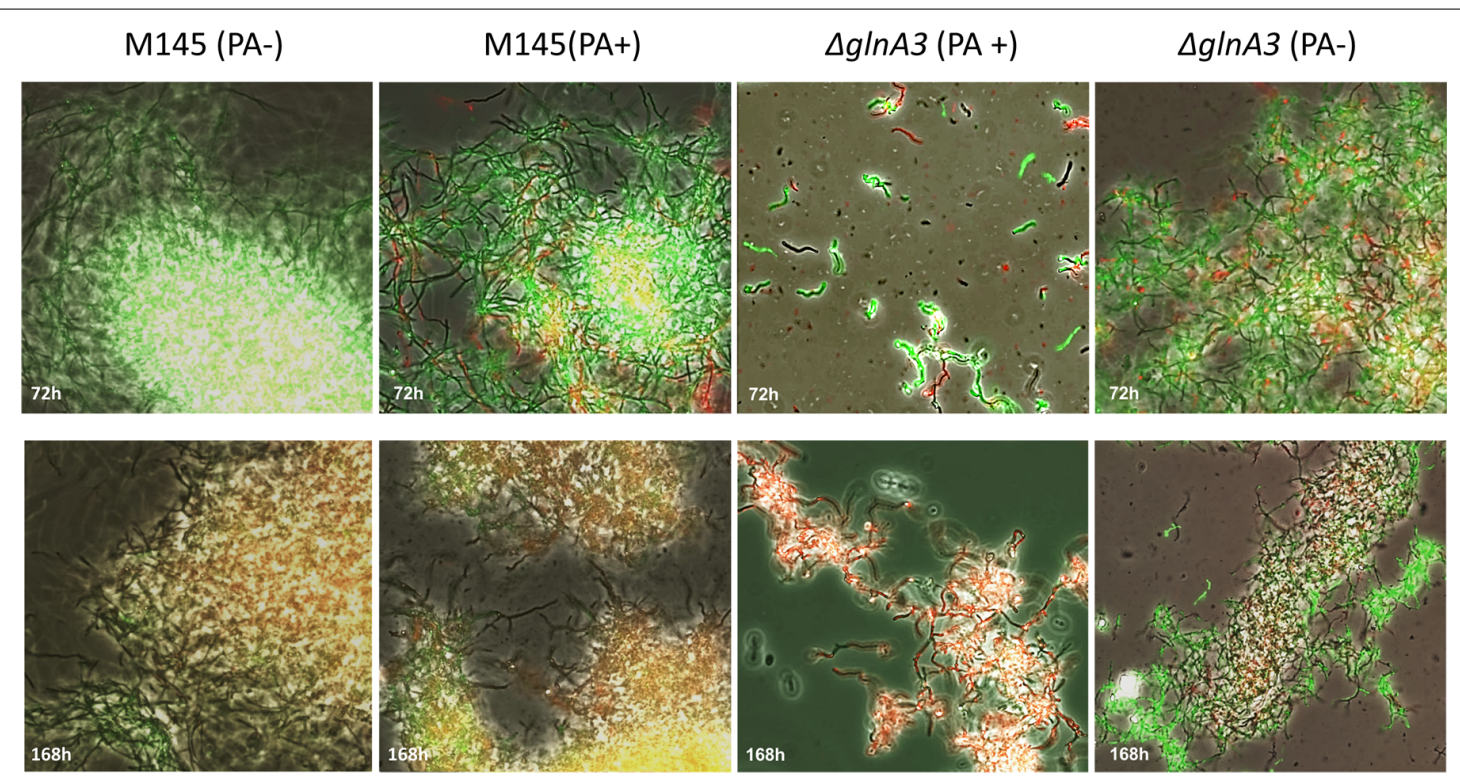

FIGURE 9 | Effect of the gInA3 deletion on cell morphology and its viability in the presence of polyamines. Parental strain S. coelicolor M145 and $\Delta$ glnA3 mutant were cultivated in YEME:TSB (1:1) medium with or without polyamines total concentration $100 \mathrm{mM}$ (putrescine, cadaverine, spermidine, and spermine, $25 \mathrm{mM}$ of each). Phase contrast microscopic pictures of parental strain M145 and $\Delta$ glnA3 mutant mycelium stained with SYTO9/PI were taken after 72 and $168 \mathrm{~h}$ of growth (under $400 \times$ enlargement). 


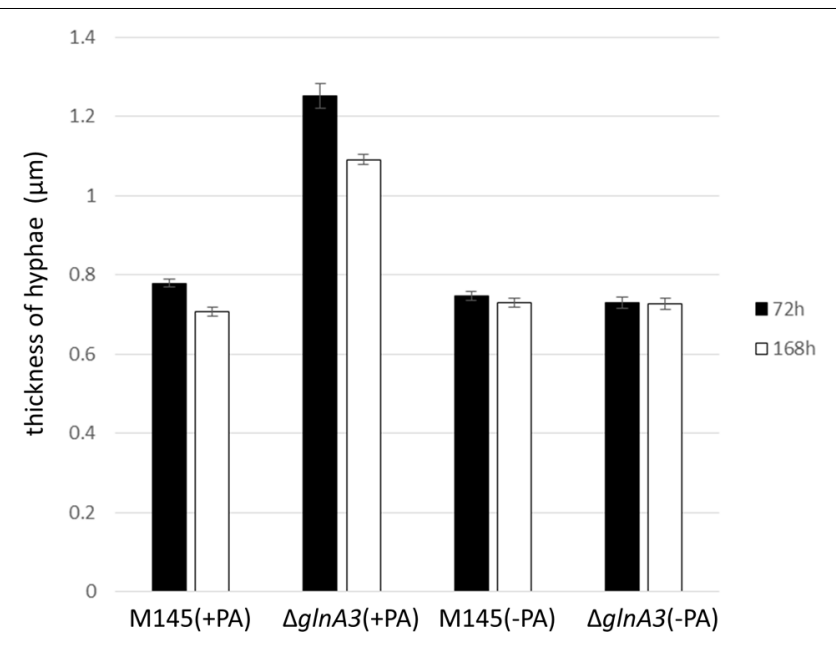

FIGURE 10 | Comparison of the hyphae thickness of parental strain S. coelicolor M145 and $\Delta$ gInA3 mutant grown in the presence of polyamines. Parental strain S. coelicolor M145 and $\Delta g / n A 3$ mutant were cultivated in YEME:TSB $(1: 1)$ medium with or without polyamines. The hyphae thickness was measured after 72 and $168 \mathrm{~h}$ of growth. Error bars indicate standard error of $n=100$ biological replicates.

lack of the conserved residues for ammonium binding as well as our observations strongly suggest that GlnA3 may function as a gamma-glutamylpolyamine synthetase catalyzing the first step of polyamine degradation.

\section{GInA3 Catalyzes Gamma-Glutamylation of Putrescine In Vitro}

To determine whether GlnA3 was able to catalyze the predicted glutamylation reaction we developed an HPLC/ESI-MS based assay designed to detect a gamma-glutamyl product formed by $\mathrm{G} \ln \mathrm{A} 3$. For this, GlnA3 was overexpressed in E. coli BL21 (DE3) and purified by nickel ion affinity chromatography. The purified His-GlnA3 was used in an in vitro assay as described in Section "Materials and Methods." The reaction conditions were as follows: $10 \mu \mathrm{g}$ of His-GlnA3 were incubated at $30^{\circ} \mathrm{C}$ with glutamate, putrescine, $\mathrm{MgCl}_{2}$ and ATP in HEPES buffer $(\mathrm{pH} 7.2)$. The reaction was stopped after $5 \mathrm{~min}$. by incubation at $100^{\circ} \mathrm{C}$ for $5 \mathrm{~min}$. HPLC analysis of generated product was performed in a positive MS mode. Result indicated that GlnA3 was able to use glutamate and putrescine as substrates in the ATP dependent reaction, generating a product with the mass to charge ratio of $218 \mathrm{~m} / z$, corresponding to calculated mass of gamma-glutamylputrescine, confirming the function of $\mathrm{Gln} \mathrm{A} 3$ as a gamma-glutamylpolyamine synthetase (Figure 11).

\section{DISCUSSION}

In this study, we demonstrated that S. coelicolor M145 is able to utilize polyamines such as putrescine, cadaverine, spermidine, and spermine as a sole nitrogen source and it is able to withstand high polyamine concentrations. Our results indicate that this ability is due to GlnA3 since the deletion of $g \ln A 3$ resulted in intracellular polyamine accumulation, abnormal morphology of the mycelial fragments as well as a polyamine sensitive phenotype resulting in cell death. Our in vivo data concerning the deletion of $g \ln A$ and $g \ln I I$ encoding GSs, GSI and GSII, respectively, indicated that GlnA3 doesn't fulfill a function of GS. Comparative in silico analysis of PauA7, GSI and GlnA3 as well as the in vitro GlnA3 enzymatic assay revealed that GlnA3 bear features of a gamma-glutamylpolyamine synthetase, an enzyme catalyzing the first step of polyamines catabolism in Streptomyces.

Using BlastP for comparative analyses of Streptomyces proteome sets (taxid: 1883), 116 homologs of the predicted GlnA3 protein were identified with $75-99 \%$ sequence identity and 95-100\% query cover in Streptomyces sp. Frequent occurrence of GlnA3 homologs in Streptomyces genomes as well as its highly conserved protein sequence in all strains indicates its evolutionary importance. Homologs of the predicted GlnA3 protein were also found in other actinobacteria such as: Nocardia spp., Rhodococcus spp., Frankia spp., Amycolatopsis spp., Kitasatospora spp., Saccharopolyspora spp. and Mycobacterium spp. (45-76\% identity and $92-100 \%$ query cover).

Since orthologs of $\mathrm{Gln} A 3$ were found also in some pathogenic actinobacteria, GlnA3 might ensure colonization and persistence in the host by conferring resistance against toxic concentrations of polyamines produced during infection. Indeed, the polyamine content was reported to increase dramatically in both proliferating cells and extracellular tissue fluids during inflammation, tissue regeneration and cell damage (Yatin, 2011). Increased polyamines levels have been demonstrated at inflammatory sites of bacterial and viral infections (Hirsch and Dubos, 1952; Colombatto et al., 1989; Clarke and Tyms, 1991; Lasbury et al., 2007). Interestingly, pathogens belonging to the actinobacteria group are able to survive in a tissue in presence of high polyamine concentrations produced by defense system in a response to infection and stress (Liao et al., 2009; Grasemann et al., 2012; Jimenez-Bremont et al., 2014). Symbiotic actinobacteria can survive in the nitrogen fixing nodules where they are constantly confronted with fluctuating polyamine concentrations (Fujihara et al., 1994). Free living $S$. coelicolor and other non-motile actinobacteria might have to cope with high concentration of polyamines that are released during the decomposition of animal cadaver and plant tissues in the soil.

The search for proteins orthologs of those involved in the catabolism of polyamine in other bacteria using BlastP and the analysis of the expression patterns of these genes, led us to predict, polyamine glutamylation pathway in $S$. coelicolor (Figure 1). We were able to show that the gamma-glutamylpolyamine synthetase GlnA3 is important for polyamine catabolism in $S$. coelicolor under the conditions tested. This implies that further post-glutamylation steps of the so far known polyamine glutamylation pathway in E. coli and $P$. aeruginosa (or a variation of this pathway) are most likely present in streptomycetes. The second step of glutamylation pathway requires a gamma-glutamyl polyamine oxidoreductase (PuuB in E. coli/pauB1-B4 in P. aeruginosa). The SCO5671 (predicted ortholog of the PuuB) showed no expression in the presence of putrescine and cadaverine, but a weak 


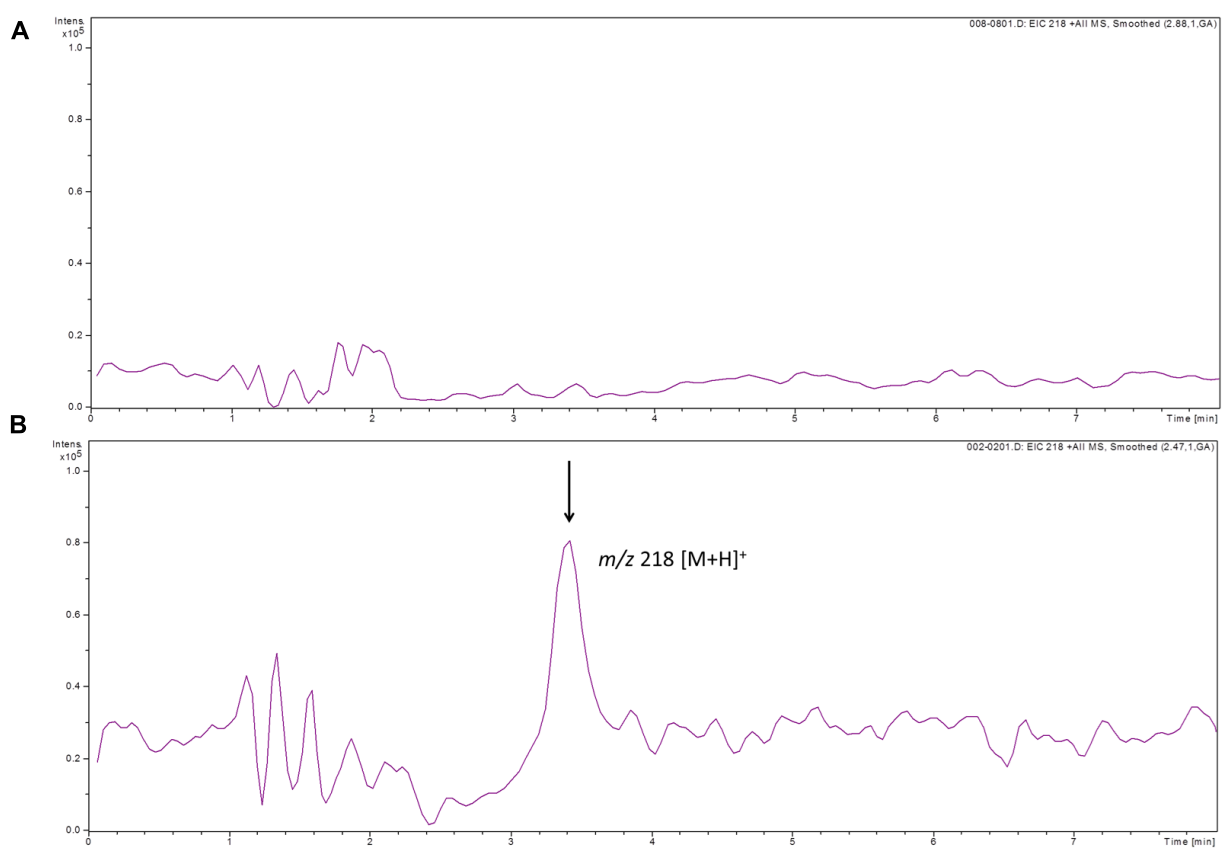

FIGURE 11 | HPLC/ESI-MS analysis of the glutamylated product generated by GInA3 in in vitro assay. Two samples were analyzed in the MS positive mode: reaction mixtures without addition of $\mathrm{G} \ln \mathrm{A} 3 \mathbf{( A )}$ and with addition of $\mathrm{G} \ln \mathrm{A} 3 \mathbf{( B )}$. Extracted ion chromatograms for the $\mathrm{G} \ln \mathrm{A} 3$ reaction product corresponding to gamma-glutamylputrescine with charge to mass ratio of $218 \mathrm{~m} / \mathrm{z}$ was shown (B), and no product in the sample without addition of GlnA3 could be detected (A).

expression has been observed in the presence of spermidine. It remains to be elucidated whether other potential homologs (SCO1281, SCO6051) with lower sequence similarity might represent gamma-glutamylpolyamine oxidoreductase PuuB in streptomycetes. The next step of the polyamine glutamylation pathway involves predicted PuuC dehydrogenase homologs (SCO5666, SCO5657), followed by the predicted hydrolase SCO6961. Last two steps of polyamine glutamylation pathway lead to the formation of succinate and are catalyzed by the predicted GabT and GabD homologs, SCO5676 and SCO5679, respectively. Interestingly, expression of the SCO5676 has been shown to be stimulated by arginine (a precursor of putrescine) in S. coelicolor M145 (Perez-Redondo et al., 2012).

Moreover, the predicted PatA aminotransferase (SCO5655), along with orthologs of additional predicted aminotransferases and dehydrogenases, suggests the possibility of an alternate pathway in streptomycetes. Interestingly, induction of the SCO5655 has been reported to be stimulated by diamide (Kallifidas et al., 2010), however, not by arginine (Perez-Redondo et al., 2012). Further genetic analysis of SCO5655 and other potential aminotransferase homologs (SCO1223, SCO1284, and SCO6769) would be required to determine whether a PatA-dependent pathway is functional. The regulation and importance of glutamylation and aminotransferase pathways may dependent on polyamine concentration or another environmental parameter such as temperature (Schneider and Reitzer, 2012).

A better knowledge of polyamine utilization in actinobacteria is of fundamental importance, since this pathway may be important for the survival strategy of pathogenic, symbiotic, and non-pathogenic actinobacteria living in as diverse habitats as human, animal, and plant tissues or in soil environment, respectively. Our work constitutes the first attempt to decipher polyamine metabolism in the actinobacterial model organism Streptomyces coelicolor via the characterization of a major polyamine resistance factor, the gamma-glutamylpolyamine synthetase GlnA3 that is indispensable for survival under high polyamine concentration.

\section{AUTHOR CONTRIBUTIONS}

$\mathrm{AM}$ performed the reverse transcriptase/PCR analysis. $\mathrm{AK}$ performed the HPLC and HPLC/MS analysis. JG constructed and analyzed the $\Delta g \ln A / g \ln I I$ mutant. NO constructed the $\Delta g \ln A 4$ mutant as well as was involved in technical assistance. NO and SK performed phenotypic analysis of all mutants and parental strain M145 on Evans medium with different nitrogen sources. SK performed complementation of the $\Delta g \ln A 3$ mutant, survival and viability assays, microscopic analysis of cells, intracellular polyamine analysis and bioinformatics analysis of DNA and protein sequences. SK cloned, overexpressed and purified GlnA3 protein and performed $\mathrm{Gln} \mathrm{A} 3$ in vitro assay. $\mathrm{AB}$ formulated the original problem and provided direction and guidance as well as designed the study and developed the methodology. $\mathrm{AB}$ generated and analyzed the model of GlnA3 structure. WW provided helpful feedback on an early draft of the paper and assisted with data analysis. $\mathrm{AB}$ contributed to the writing of the manuscript and resolved final approval of the version to be published. 


\section{FUNDING}

SK and $\mathrm{AB}$ are members of the DFG Research Training Group GRK1708 (I and II). This project as well as the Ph.D. work of SK was funded by DFG Research Training Group GRK1708 (II).

\section{ACKNOWLEDGMENTS}

We would like to thank Manuel Espinosa Padrón (Centro de Investigaciones Biológicas, CSIC, Madrid, Spain) for precious

\section{REFERENCES}

Alcazar, R., and Tiburcio, A. F. (2014). Plant polyamines in stress and development: an emerging area of research in plant sciences. Front. Plant Sci. 5:319. doi: $10.3389 /$ fpls.2014.00319

Algranati, I. D., Echandi, G., Garcia-Patrone, M., Gonzalez, N. S., and Goldemberg, S. H. (1976). Polyamines, equilibrium between ribosomal particles and protein synthesis in bacteria. Arch. Biol. Med. Exp. 10, 49-60.

Amin, R., Franz-Wachtel, M., Tiffert, Y., Heberer, M., Meky, M., Ahmed, Y., et al. (2016). Post-translational serine/threonine phosphorylation and lysine acetylation: a novel regulatory aspect of the global nitrogen response regulator GlnR in S. coelicolor M145. Front. Mol. Biosci. 3:38. doi: 10.3389/fmolb.2016. 00038

Bai, L., Chang, M., Shan, J., Jiang, R., Zhang, Y., Zhang, R., et al. (2011). Identification and characterization of a novel spermidine/spermine acetyltransferase encoded by gene ste26 from Streptomyces sp. 139. Biochimie 93, 1401-1407. doi: 10.1016/j.biochi.2011.04.014

Bercovich, Z., Snapir, Z., Keren-Paz, A., and Kahana, C. (2011). Antizyme affects cell proliferation and viability solely through regulating cellular polyamines. J. Biol. Chem. 286, 33778-33783. doi: 10.1074/jbc.M111.270637

Brickman, T. J., and Armstrong, S. K. (1996). The ornithine decarboxylase gene odc is required for alcaligin siderophore biosynthesis in Bordetella spp.: putrescine is a precursor of alcaligin. J. Bacteriol. 178, 54-60. doi: 10.1128/jb.178.1.54-60. 1996

Bullock, W. O., Fernandez, J. M., and Short, J. M. (1987). Xl1-blue - a high-efficiency plasmid transforming reca Escherichia-coli strain with betagalactosidase selection. Biotechniques 5, 376-378.

Burrell, M., Hanfrey, C. C., Kinch, L. N., Elliott, K. A., and Michael, A. J. (2012). Evolution of a novel lysine decarboxylase in siderophore biosynthesis. Mol. Microbiol. 86, 485-499. doi: 10.1111/j.1365-2958.2012.08208.x

Buttner, M. J., Chater, K. F., and Bibb, M. J. (1990). Cloning, disruption, and transcriptional analysis of three RNA polymerase sigma factor genes of Streptomyces coelicolor A3(2). J. Bacteriol. 172, 3367-3378. doi: 10.1128/jb.172. 6.3367-3378.1990

Cai, G., Sobieszczuk-Nowicka, E., Aloisi, I., Fattorini, L., Serafini-Fracassini, D., and Del Duca, S. (2015). Polyamines are common players in different facets of plant programmed cell death. Amino Acids 47, 27-44. doi: 10.1007/s00726-0141865- 1

Campilongo, R., Di Martino, M. L., Marcocci, L., Pietrangeli, P., Leuzzi, A., Grossi, M., et al. (2014). Molecular and functional profiling of the polyamine content in enteroinvasive E. coli: looking into the gap between commensal E. coli and harmful Shigella. PLoS ONE 9:e106589. doi: 10.1371/journal.pone. 0106589

Chattopadhyay, M. K., Keembiyehetty, C. N., Chen, W., and Tabor, H. (2015). Polyamines stimulate the level of the sigma38 subunit (RpoS) of Escherichia coli RNA polymerase, resulting in the induction of the glutamate decarboxylasedependent acid response system via the gadE regulon. J. Biol. Chem. 290, 17809-17821. doi: 10.1074/jbc.M115.655688

Chattopadhyay, M. K., Tabor, C. W., and Tabor, H. (2002). Absolute requirement of spermidine for growth and cell cycle progression of fission yeast (Schizosaccharomyces pombe). Proc. Natl. Acad. Sci. U.S.A. 99, 10330-10334. doi: 10.1073/pnas.162362899 time he spent reading the manuscript and for his helpful and substantial comments - always greatly appreciated. We acknowledge support by Deutsche Forschungsgemeinschaft and Open Access Publishing Fund of University of Tübingen.

\section{SUPPLEMENTARY MATERIAL}

The Supplementary Material for this article can be found online at: http://journal.frontiersin.org/article/10.3389/fmicb. 2017.00726/full\#supplementary-material

Chattopadhyay, M. K., Tabor, C. W., and Tabor, H. (2003). Polyamines protect Escherichia coli cells from the toxic effect of oxygen. Proc. Natl. Acad. Sci. U.S.A. 100, 2261-2265. doi: 10.1073/pnas.2627990100

Chattopadhyay, M. K., and Tabor, H. (2013). Polyamines are critical for the induction of the glutamate decarboxylase-dependent acid resistance system in Escherichia coli. J. Biol. Chem. 288, 33559-33570. doi: 10.1074/jbc.M113. 510552

Clarke, J. R., and Tyms, A. S. (1991). Polyamine biosynthesis in cells infected with different clinical isolates of human cytomegalovirus. J. Med. Virol. 34, 212-216. doi: 10.1002/jmv.1890340403

Colombatto, S., De Agostini, M., Corsi, D., and Sinicco, A. (1989). Polyamines in lymphocytes from patients infected by human immunodeficiency virus. Biol. Chem. Hoppe Seyler 370, 745-748. doi: 10.1515/bchm3.1989.370.2.745

Cunningham-Rundles, S., and Maas, W. K. (1975). Isolation, characterization, and mapping of Escherichia coli mutants blocked in the synthesis of ornithine decarboxylase. J. Bacteriol. 124, 791-799.

Datsenko, K. A., and Wanner, B. L. (2000). One-step inactivation of chromosomal genes in Escherichia coli K-12 using PCR products. Proc. Natl. Acad. Sci. U.S.A. 97, 6640-6645. doi: 10.1073/pnas.120163297

Davis, R. H., and Ristow, J. L. (1991). Polyamine toxicity in Neurospora crassa: protective role of the vacuole. Arch. Biochem. Biophys. 285, 306-311. doi: 10.1016/0003-9861(91)90364-O

Dudkowska, M., Lai, J., Gardini, G., Stachurska, A., Grzelakowska-Sztabert, B., Colombatto, S., et al. (2003). Agmatine modulates the in vivo biosynthesis and interconversion of polyamines and cell proliferation. Biochim. Biophys. Acta 1619, 159-166. doi: 10.1016/S0304-4165(02)00476-2

Evans, C. G. T., Herbert, D., and Tempest, D. W. (1970). Chapter XIII the continuous cultivation of micro-organisms: 2. construction of a chemostat. Methods Microbiol. 2, 277-327. doi: 10.1016/S0580-9517(08) 70227-7

Fink, D., Falke, D., Wohlleben, W., and Engels, A. (1999). Nitrogen metabolism in Streptomyces coelicolor A3(2): modification of glutamine synthetase I by an adenylyltransferase. Microbiology 145(Pt 9), 2313-2322. doi: 10.1099/ 00221287-145-9-2313

Forouhar, F., Lee, I. S., Vujcic, J., Vujcic, S., Shen, J., Vorobiev, S. M., et al. (2005). Structural and functional evidence for Bacillus subtilis PaiA as a novel N1-spermidine/spermine acetyltransferase. J. Biol. Chem. 280, 40328-40336. doi: 10.1074/jbc.M505332200

Foster, A., Barnes, N., Speight, R., and Keane, M. A. (2013). Genomic organisation, activity and distribution analysis of the microbial putrescine oxidase degradation pathway. Syst. Appl. Microbiol. 36, 457-466. doi: 10.1016/j. syapm.2013.06.008

Fujihara, S., Abe, H., Minakawa, Y., Akao, S., and Yoneyama, T. (1994). Polyamines in nodules from various plant-microbe symbiotic associations. Plant Cell Physiol. 35, 1127-1134. doi: 10.1093/oxfordjournals.pcp.a078705

Grasemann, H., Shehnaz, D., Enomoto, M., Leadley, M., Belik, J., and Ratjen, F. (2012). L-ornithine derived polyamines in cystic fibrosis airways. PLoS ONE 7:e46618. doi: 10.1371/journal.pone.0046618

Griffiths, G. L., Sigel, S. P., Payne, S. M., and Neilands, J. B. (1984). Vibriobactin, a siderophore from Vibrio cholerae. J. Biol. Chem. 259, 383-385.

Gust, B., Challis, G. L., Fowler, K., Kieser, T., and Chater, K. F. (2003). PCRtargeted Streptomyces gene replacement identifies a protein domain needed for 
biosynthesis of the sesquiterpene soil odor geosmin. Proc. Natl. Acad. Sci. U.S.A. 100, 1541-1546. doi: 10.1073/pnas. 0337542100

Harth, G., Maslesa-Galic, S., Tullius, M. V., and Horwitz, M. A. (2005). All four Mycobacterium tuberculosis glnA genes encode glutamine synthetase activities but only $\mathrm{Gln} A 1$ is abundantly expressed and essential for bacterial homeostasis. Mol. Microbiol. 58, 1157-1172. doi: 10.1111/j.1365-2958.2005.04899.x

Hatmi, S., Trotel-Aziz, P., Villaume, S., Couderchet, M., Clement, C., and Aziz, A. (2014). Osmotic stress-induced polyamine oxidation mediates defence responses and reduces stress-enhanced grapevine susceptibility to Botrytis cinerea. J. Exp. Bot. 65, 75-88. doi: 10.1093/jxb/ert351

Hayward, D., Van Helden, P. D., and Wiid, I. J. (2009). Glutamine synthetase sequence evolution in the mycobacteria and their use as molecular markers for Actinobacteria speciation. BMC Evol. Biol. 9:48. doi: 10.1186/1471-2148-9-48

Heby, O. (1981). Role of polyamines in the control of cell proliferation and differentiation. Differentiation 19, 1-20. doi: 10.1111/j.1432-0436.1981. tb01123.x

Higashi, K., Kashiwagi, K., Taniguchi, S., Terui, Y., Yamamoto, K., Ishihama, A., et al. (2006). Enhancement of +1 frameshift by polyamines during translation of polypeptide release factor 2 in Escherichia coli. J. Biol. Chem. 281, 9527-9537. doi: 10.1074/jbc.M513752200

Hillemann, D., Dammann, T., Hillemann, A., and Wohlleben, W. (1993). Genetic and biochemical characterization of the two glutamine synthetases GSI and GSII of the phosphinothricyl-alanyl-alanine producer, Streptomyces viridochromeogenes Tu494. J. Gen. Microbiol. 139, 1773-1783. doi: 10.1099/ 00221287-139-8-1773

Hirsch, J. G., and Dubos, R. J. (1952). The effect of spermine on tubercle bacilli. J. Exp. Med. 95, 191-208. doi: 10.1084/jem.95.2.191

Huang, S. C., Panagiotidis, C. A., and Canellakis, E. S. (1990). Transcriptional effects of polyamines on ribosomal proteins and on polyamine-synthesizing enzymes in Escherichia coli. Proc. Natl. Acad. Sci. U.S.A. 87, 3464-3468. doi: 10.1073/pnas.87.9.3464

Igarashi, K., and Kashiwagi, K. (2006). Polyamine Modulon in Escherichia coli: genes involved in the stimulation of cell growth by polyamines. J. Biochem. 139, 11-16. doi: 10.1093/jb/mvj020

Jain, A., and Tyagi, A. K. (1987). Role of polyamines in the synthesis of RNA in mycobacteria. Mol. Cell. Biochem. 78, 3-8. doi: 10.1007/BF00224418

Jimenez-Bremont, J. F., Marina, M., Guerrero-Gonzalez, M. d. L., Rossi, F. R., Sanchez-Rangel, D., Rodriguez-Kessler, M., et al. (2014). Physiological and molecular implications of plant polyamine metabolism during biotic interactions. Front. Plant Sci. 5:95. doi: 10.3389/fpls.2014.00095

Jung, I. L., and Kim, I. G. (2003a). Polyamines and glutamate decarboxylase-based acid resistance in Escherichia coli. J. Biol. Chem. 278, 22846-22852.

Jung, I. L., and Kim, I. G. (2003b). Transcription of ahpC, katG, and katE genes in Escherichia coli is regulated by polyamines: polyamine-deficient mutant sensitive to $\mathrm{H}_{2} \mathrm{O}_{2}$-induced oxidative damage. Biochem. Biophys. Res. Commun. 301, 915-922.

Kallifidas, D., Thomas, D., Doughty, P., and Paget, M. S. (2010). The sigmaR regulon of Streptomyces coelicolor A32 reveals a key role in protein quality control during disulphide stress. Microbiology 156, 1661-1672. doi: 10.1099/ mic. $0.037804-0$

Kieser, T., Bibb, M. J., Buttner, M. J., Chater, K. F., and Hopwood, D. A. (2000). Practical Streptomyces Genetics. Norwich: John Innes Foundation.

Kurihara, S., Oda, S., Kato, K., Kim, H. G., Koyanagi, T., Kumagai, H., et al. (2005). A novel putrescine utilization pathway involves gamma-glutamylated intermediates of Escherichia coli K-12. J. Biol. Chem. 280, 4602-4608. doi: $10.1074 /$ jbc.M411114200

Kusano, T., and Suzuki, H. (eds). (2015). Polyamines: A Universal Molecular Nexus for Growth, Survival, and Specialized Metabolism. Tokyo: Springer.

Kwon, D. H., and Lu, C. D. (2006). Polyamines induce resistance to cationic peptide, aminoglycoside, and quinolone antibiotics in Pseudomonas aeruginosa PAO1. Antimicrob. Agents Chemother. 50, 1615-1622. doi: 10.1128/AAC.50.5. $1615-1622.2006$

Ladner, J. E., Atanasova, V., Dolezelova, Z., and Parsons, J. F. (2012). Structure and activity of PA5508, a hexameric glutamine synthetase homologue. Biochemistry 51, 10121-10123. doi: 10.1021/bi3014856

Lasbury, M. E., Merali, S., Durant, P. J., Tschang, D., Ray, C. A., and Lee, C. H. (2007). Polyamine-mediated apoptosis of alveolar macrophages during
Pneumocystis pneumonia. J. Biol. Chem. 282, 11009-11020. doi: 10.1074/jbc. M611686200

Lee, J., Sperandio, V., Frantz, D. E., Longgood, J., Camilli, A., Phillips, M. A., et al. (2009). An alternative polyamine biosynthetic pathway is widespread in bacteria and essential for biofilm formation in Vibrio cholerae. J. Biol. Chem. 284, 9899-9907. doi: 10.1074/jbc.M900110200

Li, Z., Kessler, W., Van Den Heuvel, J., and Rinas, U. (2011). Simple defined autoinduction medium for high-level recombinant protein production using T7-based Escherichia coli expression systems. Appl. Microbiol. Biotechnol. 91, 1203-1213. doi: 10.1007/s00253-011-3407-z

Liao, C. P., Phanstiel, O. T., Lasbury, M. E., Zhang, C., Shao, S., Durant, P. J., et al. (2009). Polyamine transport as a target for treatment of Pneumocystis pneumonia. Antimicrob. Agents Chemother. 53, 5259-5264. doi: 10.1128/AAC. 00662-09

Liu, J. H., Wang, W., Wu, H., Gong, X., and Moriguchi, T. (2015). Polyamines function in stress tolerance: from synthesis to regulation. Front. Plant Sci. 6:827. doi: $10.3389 /$ fpls.2015.00827

MacNeil, D. J., Occi, J. L., Gewain, K. M., Macneil, T., Gibbons, P. H., Ruby, C. L., et al. (1992). Complex organization of the Streptomyces avermitilis genes encoding the avermectin polyketide synthase. Gene 115, 119-125. doi: 10.1016/ 0378-1119(92)90549-5

Maeda, T., Wakasawa, T., Shima, Y., Tsuboi, I., Aizawa, S., and Tamai, I. (2006). Role of polyamines derived from arginine in differentiation and proliferation of human blood cells. Biol. Pharm. Bull. 29, 234-239. doi: 10.1248/bpb. 29.234

Menges, R., Muth, G., Wohlleben, W., and Stegmann, E. (2007). The ABC transporter Tba of Amycolatopsis balhimycina is required for efficient export of the glycopeptide antibiotic balhimycin. Appl. Microbiol. Biotechnol. 77, 125-134. doi: 10.1007/s00253-007-1139-x

Miller-Fleming, L., Olin-Sandoval, V., Campbell, K., and Ralser, M. (2015). Remaining mysteries of molecular biology: the role of polyamines in the cell. J. Mol. Biol. 427, 3389-3406. doi: 10.1016/j.jmb.2015.06.020

Minocha, R., Majumdar, R., and Minocha, S. C. (2014). Polyamines and abiotic stress in plants: a complex relationship. Front. Plant Sci. 5:175. doi: 10.3389/ fpls.2014.00175

Mo, H., Wang, X., Zhang, Y., Zhang, G., Zhang, J., and Ma, Z. (2015). Cotton polyamine oxidase is required for spermine and camalexin signalling in the defence response to Verticillium dahliae. Plant J. 83, 962-975. doi: 10.1111/tpj. 12941

Moschou, P. N., and Roubelakis-Angelakis, K. A. (2014). Polyamines and programmed cell death. J. Exp. Bot. 65, 1285-1296. doi: 10.1093/jxb/ert373

Nastri, H. G., and Algranati, I. D. (1996). Effect of polyamines on plasmid-mediated kanamycin resistance and kanamycin phosphotransferase gene expression in Escherichia coli. Cell. Mol. Biol. 42, 711-717.

Nastri, H. G., Fastame, I. G., and Algranati, I. D. (1993). Polyamines modulate streptomycin-induced mistranslation in Escherichia coli. Biochim. Biophys. Acta 1216, 455-459. doi: 10.1016/0167-4781(93)90014-5

Nentwich, M. (2010). Die Funktion von GlnA2 in der Transkriptionellen und Posttranslationalen Kontrolle des Stickstoffmetabolismus in Streptomyces coelicolor M145. Doctoral Dissertation, Eberhard Karls Universität Tübingen, Tübingen.

Nesse, L. L., Berg, K., and Vestby, L. K. (2015). Effects of norspermidine and spermidine on biofilm formation by potentially pathogenic Escherichia coli and Salmonella enterica wild-type strains. Appl. Environ. Microbiol. 81, 2226-2232. doi: 10.1128/AEM.03518-14

Nguyen, A. Q., Schneider, J., and Wendisch, V. F. (2015). Elimination of polyamine $\mathrm{N}$-acetylation and regulatory engineering improved putrescine production by Corynebacterium glutamicum. J. Biotechnol. 201, 75-85. doi: 10.1016/j.jbiotec. 2014.10.035

Norris, V., Reusch, R. N., Igarashi, K., and Root-Bernstein, R. (2015). Molecular complementarity between simple, universal molecules and ions limited phenotype space in the precursors of cells. Biol. Direct 10, 28. doi: 10.1186/ s13062-014-0028-3

Odenlund, M., Holmqvist, B., Baldetorp, B., Hellstrand, P., and Nilsson, B. O. (2009). Polyamine synthesis inhibition induces $S$ phase cell cycle arrest in vascular smooth muscle cells. Amino Acids 36, 273-282. doi: 10.1007/s00726008-0060-7 
Oh, T. J., and Kim, I. G. (1999). The expression of Escherichia coli SOS genes recA and uvrA is inducible by polyamines. Biochem. Biophys. Res. Commun. 264, 584-589. doi: 10.1006/bbrc.1999.1553

Okanishi, M., Suzuki, K., and Umezawa, H. (1974). Formation and reversion of Streptomycete protoplasts: cultural condition and morphological study. J. Gen. Microbiol. 80, 389-400. doi: 10.1099/00221287-80-2-389

Oves-Costales, D., Kadi, N., Fogg, M. J., Song, L., Wilson, K. S., and Challis, G. L. (2008). Petrobactin biosynthesis: AsbB catalyzes condensation of spermidine with N8-citryl-spermidine and its N1-(3,4-dihydroxybenzoyl) derivative. Chem. Commun. (Camb.) 4034-4036. doi: 10.1039/b809353a

Pal, M., Szalai, G., and Janda, T. (2015). Speculation: polyamines are important in abiotic stress signaling. Plant Sci. 237, 16-23. doi: 10.1016/j.plantsci.2015.05.003

Parhamifar, L., Andersen, H., Wu, L., Hall, A., Hudzech, D., and Moghimi, S. M. (2014). Polycation-mediated integrated cell death processes. Adv. Genet. 88, 353-398. doi: 10.1016/B978-0-12-800148-6.00012-2

Pegg, A. E. (2013). Toxicity of polyamines and their metabolic products. Chem. Res. Toxicol. 26, 1782-1800. doi: 10.1021/tx400316s

Perez-Redondo, R., Rodriguez-Garcia, A., Botas, A., Santamarta, I., Martin, J. F., and Liras, P. (2012). ArgR of Streptomyces coelicolor is a versatile regulator. PLoS ONE 7:e32697. doi: 10.1371/journal.pone.0032697

Pirnes-Karhu, S., Maatta, J., Finnila, M., Alhonen, L., and Uimari, A. (2015). Overexpression of spermidine/spermine N1-acetyltransferase impairs osteoblastogenesis and alters mouse bone phenotype. Transgenic Res. 24, 253-265. doi: 10.1007/s11248-014-9836-6

Pitkin, J., and Davis, R. H. (1990). The genetics of polyamine synthesis in Neurospora crassa. Arch. Biochem. Biophys. 278, 386-391. doi: 10.1016/00039861(90)90275-4

Planet, P. J., Larussa, S. J., Dana, A., Smith, H., Xu, A., Ryan, C., et al. (2013). Emergence of the epidemic methicillin-resistant Staphylococcus aureus strain USA300 coincides with horizontal transfer of the arginine catabolic mobile element and speG-mediated adaptations for survival on skin. mBio 4:e00889-13. doi: $10.1128 / \mathrm{mBio} .00889-13$

Potter, A. J., and Paton, J. C. (2014). Spermidine biosynthesis and transport modulate pneumococcal autolysis. J. Bacteriol. 196, 3556-3561. doi: 10.1128/ JB.01981- 14

Ray, R. M., Zimmerman, B. J., Mccormack, S. A., Patel, T. B., and Johnson, L. R. (1999). Polyamine depletion arrests cell cycle and induces inhibitors p21(Waf1/Cip1), p27(Kip1), and p53 in IEC-6 cells. Am. J. Physiol. 276, C684-C691.

Redenbach, M., Kieser, H. M., Denapaite, D., Eichner, A., Cullum, J., Kinashi, H., et al. (1996). A set of ordered cosmids and a detailed genetic and physical map for the $8 \mathrm{Mb}$ Streptomyces coelicolor A3(2) chromosome. Mol. Microbiol. 21, 77-96. doi: 10.1046/j.1365-2958.1996.6191336.x

Reis, R. S., Vale Ede, M., Heringer, A. S., Santa-Catarina, C., and Silveira, V. (2016). Putrescine induces somatic embryo development and proteomic changes in embryogenic callus of sugarcane. J. Proteomics 130, 170-179. doi: 10.1016/j. jprot.2015.09.029

Reuther J., and Wohlleben W. (2007). Nitrogen metabolism in streptomyces coelicolor: transcriptional and post-translational regulation. J. Mol. Microbiol. Biotechnol. 12, 139-146. doi: 10.1159/000096469

Rexer, H. U., Schaberle, T., Wohlleben, W., and Engels, A. (2006). Investigation of the functional properties and regulation of three glutamine synthetaselike genes in Streptomyces coelicolor A3(2). Arch. Microbiol. 186, 447-458. doi: 10.1007/s00203-006-0159-8

Rossi, F. R., Marina, M., and Pieckenstain, F. L. (2015). Role of Arginine decarboxylase (ADC) in Arabidopsis thaliana defence against the pathogenic bacterium Pseudomonas viridiflava. Plant Biol. 17, 831-839. doi: 10.1111/plb. 12289

Sakamoto, A., Terui, Y., Yoshida, T., Yamamoto, T., Suzuki, H., Yamamoto, K., et al. (2015). Three members of polyamine modulon under oxidative stress conditions: two transcription factors (SoxR and EmrR) and a glutathione synthetic enzyme (GshA). PLoS ONE 10:e0124883. doi: 10.1371/journal.pone. 0124883

Sarathy, J. P., Lee, E., and Dartois, V. (2013). Polyamines inhibit porin-mediated fluoroquinolone uptake in mycobacteria. PLoS ONE 8:e65806. doi: 10.1371/ journal.pone.0065806

Sarkar, N. K., Shankar, S., and Tyagi, A. K. (1995). Polyamines exert regulatory control on mycobacterial transcription: a study using RNA polymerase from Mycobacterium phlei. Biochem. Mol. Biol. Int. 35, 1189-1198.

Schneider, B. L., Hernandez, V. J., and Reitzer, L. (2013). Putrescine catabolism is a metabolic response to several stresses in Escherichia coli. Mol. Microbiol. 88, 537-550. doi: 10.1111/mmi.12207

Schneider, B. L., and Reitzer, L. (2012). Pathway and enzyme redundancy in putrescine catabolism in Escherichia coli. J. Bacteriol. 194, 4080-4088. doi: 10.1128/JB.05063-11

Sekowska, A., Bertin, P., and Danchin, A. (1998). Characterization of polyamine synthesis pathway in Bacillus subtilis 168. Mol. Microbiol. 29, 851-858. doi: 10.1046/j.1365-2958.1998.00979.x

Shaibe, E., Metzer, E., and Halpern, Y. S. (1985). Metabolic pathway for the utilization of L-arginine, L-ornithine, agmatine, and putrescine as nitrogen sources in Escherichia coli K-12. J. Bacteriol. 163, 933-937.

Studier, F. W. (2014). Stable expression clones and auto-induction for protein production in E. coli. Methods Mol. Biol. 1091, 17-32. doi: 10.1007/978-162703-691-7_2

Tabor, C. W., and Tabor, H. (1985). Polyamines in microorganisms. Microbiol. Rev. 49, 81-99.

Terui, Y., Akiyama, M., Sakamoto, A., Tomitori, H., Yamamoto, K., Ishihama, A., et al. (2012). Increase in cell viability by polyamines through stimulation of the synthesis of ppGpp regulatory protein and omega protein of RNA polymerase in Escherichia coli. Int. J. Biochem. Cell Biol. 44, 412-422. doi: 10.1016/j.biocel. 2011.11.017

Tiffert, Y., Franz-Wachtel, M., Fladerer, C., Nordheim, A., Reuther, J., Wohlleben, W., et al. (2011). Proteomic analysis of the GlnR-mediated response to nitrogen limitation in Streptomyces coelicolor M145. Appl. Microbiol. Biotechnol. 89, 1149-1159. doi: 10.1007/s00253-011-3086-9

Tkachenko, A. G., and Nesterova, L. Y. (2003). Polyamines as modulators of gene expression under oxidative stress in Escherichia coli. Biochemistry 68, 850-856.

Tkachenko, A. G., Pozhidaeva, O. N., and Shumkov, M. S. (2006). Role of polyamines in formation of multiple antibiotic resistance of Escherichia coli under stress conditions. Biochemistry 71, 1042-1049. doi: 10.1134/ s0006297906090148

Tome, M. E., Fiser, S. M., Payne, C. M., and Gerner, E. W. (1997). Excess putrescine accumulation inhibits the formation of modified eukaryotic initiation factor $5 \mathrm{~A}$ (eIF-5A) and induces apoptosis. Biochem. J. 328(Pt 3), 847-854. doi: 10.1042/ bj3280847

Tsaniklidis, G., Kotsiras, A., Tsafouros, A., Roussos, P. A., Aivalakis, G., Katinakis, P., et al. (2016). Spatial and temporal distribution of genes involved in polyamine metabolism during tomato fruit development. Plant Physiol. Biochem. 100, 27-36. doi: 10.1016/j.plaphy.2016.01.001

Valdes-Santiago, L., and Ruiz-Herrera, J. (2013). Stress and polyamine metabolism in fungi. Front. Chem. 1:42. doi: 10.3389/fchem.2013.00042

Volff, J. N., Eichenseer, C., Viell, P., Piendl, W., and Altenbuchner, J. (1996). Nucleotide sequence and role in DNA amplification of the direct repeats composing the amplifiable element AUD1 of Streptomyces lividans 66. Mol. Microbiol. 21, 1037-1047. doi: 10.1046/j.1365-2958.1996.761428.x

Walters, D. R. (2003). Polyamines and plant disease. Phytochemistry 64, 97-107. doi: 10.1016/S0031-9422(03)00329-7

Weiger, T. M., and Hermann, A. (2014). Cell proliferation, potassium channels, polyamines and their interactions: a mini review. Amino Acids 46, 681-688. doi: 10.1007/s00726-013-1536-7

Weisschuh, N., Fink, D., Vierling, S., Bibb, M. J., Wohlleben, W., and Engels, A. (2000). Transcriptional analysis of the gene for glutamine synthetase II and two upstream genes in Streptomyces coelicolor A3(2). Mol. Gen. Genet. 264, 461-469. doi: $10.1007 /$ s004380000315

Wimalasekera, R., Tebartz, F., and Scherer, G. F. (2011). Polyamines, polyamine oxidases and nitric oxide in development, abiotic and biotic stresses. Plant Sci. 181, 593-603. doi: 10.1016/j.plantsci.2011.04.002

Wortham, B. W., Patel, C. N., and Oliveira, M. A. (2007). Polyamines in bacteria: pleiotropic effects yet specific mechanisms. Adv. Exp. Med. Biol. 603, 106-115. doi: 10.1007/978-0-387-72124-8_9

Yao, X., He, W., and Lu, C. D. (2011). Functional characterization of seven gammaGlutamylpolyamine synthetase genes and the bauRABCD locus for polyamine and beta-Alanine utilization in Pseudomonas aeruginosa PAO1. J. Bacteriol. 193, 3923-3930. doi: 10.1128/JB.05105-11 
Yatin, M. (2011). Polyamines in living organisms. J. Cell Mol. Biol. 1, 57-67.

Yoshida, M., Kashiwagi, K., Shigemasa, A., Taniguchi, S., Yamamoto, K., Makinoshima, H., et al. (2004). A unifying model for the role of polyamines in bacterial cell growth, the polyamine modulon. J. Biol. Chem. 279, 46008-46013. doi: $10.1074 /$ jbc.M404393200

Zeier, J. (2013). New insights into the regulation of plant immunity by amino acid metabolic pathways. Plant Cell Environ. 36, 2085-2103. doi: 10.1111/pce. 12122

Zhou, Y., Ma, C., Karmouch, J., Katbi, H. A., and Liu, X. J. (2009). Antiapoptotic role for ornithine decarboxylase during oocyte maturation. Mol. Cell. Biol. 29, 1786-1795. doi: 10.1128/MCB.01815-08
Conflict of Interest Statement: The authors declare that the research was conducted in the absence of any commercial or financial relationships that could be construed as a potential conflict of interest.

Copyright (® 2017 Krysenko, Okoniewski, Kulik, Matthews, Grimpo, Wohlleben and Bera. This is an open-access article distributed under the terms of the Creative Commons Attribution License (CC BY). The use, distribution or reproduction in other forums is permitted, provided the original author(s) or licensor are credited and that the original publication in this journal is cited, in accordance with accepted academic practice. No use, distribution or reproduction is permitted which does not comply with these terms. 